\title{
Metabolic response of Botryococcus braunii to high bicarbonate dosages and other conditions: analysis of photosynthetic performance, productivity, and lipidomic profile
}

\author{
Néstor David Giraldo ${ }^{1}$ (D) Sandra Marcela Correa ${ }^{2}$ (D) . Andrés Arbeláez ${ }^{1}$ (D) Felix L. Figueroa ${ }^{3}$ (D) . \\ Rigoberto Ríos-Estepa ${ }^{4}$ (D) - Lucía Atehortúa ${ }^{1}$ (D)
}

Received: 5 March 2021 / Revised and accepted: 14 June 2021 / Published online: 14 August 2021

(c) The Author(s) 2021

\begin{abstract}
In this study the metabolic responses of Botryococcus braunii were analyzed upon different inorganic carbon dosages and nutrient limitation conditions in terms of lipid and biomass productivity, as well as photosynthetic performance. The nutritional schemes evaluated included different levels of sodium bicarbonate and nitrogen and phosphorus starvation, which were contrasted against standard cultures fed with $\mathrm{CO}_{2}$. Bicarbonate was found to be an advantageous carbon source since high dosages caused a significant increase in biomass and lipid productivity, in addition to an enhanced photosynthetic quantum yield and neutral lipids abundance. This contrasts to the commonly used approach of microalgae nutrient limitation, which leads to high lipid accumulation at the expense of impaired cellular growth, causing a decline in overall lipid productivity. The lipidome analysis served to hypothesize about the influence of the nutritional context on $B$. braunii structural and storage lipid metabolism, besides the adaptive responses exhibited by cells that underwent nutrient stress.
\end{abstract}

Keywords Biofuels · Biorefinery $\cdot$ Botryococcus braunii $\cdot$ Chlorophyceae $\cdot$ Lipidomics $\cdot$ Photosynthesis

\section{Introduction}

The rapid growth of human population, together with improved living standards, has triggered an intensification of the per capita consumption of goods. This acceleration has resulted in greater greenhouse gas emissions due to the massive use of fossil energy sources. Taking into account the current demographic projections (Cleland 2013), such context urges a transition from an oil-based industrial infrastructure

Sandra Marcela Correa

Cordoba@mpimp-golm.mpg.de

1 Grupo de Biotecnología, Instituto de Biología, Facultad de Ciencias Exactas y Naturales, Universidad de Antioquia UdeA, Calle 67 No. 53-108, Medellín, Colombia

2 Max Planck Institute of Molecular Plant Physiology, Am Mühlenberg 1, Potsdam, Germany

3 Institute of Biotechnology and Blue Development (IBYDA), Malaga University, Campus Universitario de Teatinos s/n, 29071 Malaga, Spain

4 Grupo de Bioprocesos, Departamento de Ingeniería Química, Universidad de Antioquia UdeA, Calle 67 No. 53-108, Medellín, Colombia towards novel alternatives with neutral or negative $\mathrm{CO}_{2}$ footprint. Accordingly, the development, implementation, and improvement of biotechnological processes designed for carbon recovery and re-utilization as green fuel supply are the top trending scientific aims currently being addressed to contribute in the upcoming global transition (Head and Gray 2016; Kilbane 2016; Singhal and Prashant 2020).

Hence, one of the most broadly studied processes in recent decades has been the use of the natural photosynthesis process carried out by microalgae to fix $\mathrm{CO}_{2}$ using light as energy source for the production of fuels and industrially valuable compounds (Arun et al. 2020). One of the strains that has drawn the attention in this regard is Botryococcus braunii, a green alga recognized for its ability to synthesize long-chain hydrocarbons whose chemical structure varies according to a specific algal chemotype (Banerjee et al. 2002; Cheng et al. 2013). So far, B. braunii strains have been categorized into four major groups according to the chemical structure of the hydrocarbons produced by each chemotype. The $A$ race produces alkadienes and alcatrienes $\left(C_{25}-C_{31}\right)$ derived from oleic acid that accounts from less than 1 up to $60 \%$ of total biomass (Metzger et al. 1985, 1997). The B race chemotype has been the most widely studied group, and 
some strains within it are recognized for producing unsaturated poly-methylated triterpene-like lipids known as botryococcenes $\left(\mathrm{C}_{\mathrm{n}} \mathrm{H}_{2 \mathrm{n}-10}, n=30-37\right)$ which represent $8-35 \%$ of total biomass (Okada et al. 1995, 1997; Yoshimura et al. 2013). Other less studied groups are known such as the $L$ race which produces $3-7.5 \%$ of a single hydrocarbon known as licopadiene $\left(\mathrm{C}_{40} \mathrm{H}_{78}\right)$, and the $\mathrm{S}$ race that accumulates an epoxy-n-alkane and a saturated n-alkane with fatty acyl length of $\mathrm{C}_{18}$ and $\mathrm{C}_{20}$, respectively (Gouveia et al. 2017).

Even though the unique chemical characteristics of $B$. braunii biomass makes it suitable for future energetic exploitation, the use of this strain as a realistic alternative for bioenergy production is hampered by its slow growth and low productivity (Kleinert and Griehl 2020). Consequently, a number of studies have addressed the partial elucidation of the pathways of lipid metabolism with two main purposes: (i) identifying metabolic targets that could potentially be tuned for reaching higher lipid yields (Wolf et al. 1985; Metzger et al. 1986; Niehaus et al. 2011; Molnár et al. 2012); and (ii) identifying key enzymatic steps in order to engineer fast-growing organisms (Niehaus et al. 2012; Bell et al. 2014; Muzika et al. 2015; Zhuang and Chappell 2015; Thapa et al. 2016). Although the progress of these two strategies has brought fundamental insights about the hydrocarbon biochemistry in B. brau$n i i$, especially for the $\mathrm{B}$ race, the complete mechanisms still remain unclear and only marginal improvements have been achieved (Jin et al. 2016; Cheng et al. 2019). Furthermore, the use of genetically modified organisms is an important constraint to consider at larger industrial scales due to strict regulatory matters and public opinion concerns (Guleria and Kumar 2020). On the other hand, an alternative approach that has been traditionally used to upgrade the production features of algal processes consists of empirically optimizing the reactor design and culture variables. Parameters including but not limited to media composition (Dayananda et al. 2007), temperature (Kalacheva et al. 2002), pH (Murprayana et al. 2021), light quality, and quantity (Şengül et al. 2019) have been studied to identify optimal operation conditions for boosting $B$. braunii productivity. For instance, increased lipid content has been stimulated via nutrient limitation (Fang et al. 2015) or addition of elicitors (Ermavitalini et al. 2017; Du et al. 2020). The modulation of the type and quantity of the carbon source supplied to B. braunii cells has also served as a strategy to promote growth and lipid accumulation. Ranga Rao et al. (2007) evaluated the enrichment of the inflow gas by adding $2 \%(\mathrm{v} / \mathrm{v}) \mathrm{CO}_{2}$, which caused a twofold increase in final biomass and carotenoid content in B. braunii 572, together with a 2.5-threefold increase in palmitic and oleic acid levels compared to the controls. Alternatively, other studies have suggested that instead of $\mathrm{CO}_{2}$, the use of bicarbonate up to $20 \mathrm{mM}$ can not only promote algal growth, but also improve carbon use efficiency (Kim et al. 2017; Salbitani et al. 2019). Moreover, Tu et al. (2018) showed that high dosages of bicarbonate (up to $80 \mathrm{~g} \mathrm{~L}^{-1}$ ) had antibacterial activity and significantly promoted Chlorella sp. growth and lipid production. Conversely, Tanoi et al. (2011) indicated that bicarbonate concentrations over $2.5 \mathrm{mM}$ are detrimental for $B$. braunii $\mathrm{B} 70$ growth, opening the question of whether $B$. braunii 572 could tolerate high bicarbonate concentrations and how such conditions would affect cell physiology and the bioprocess performance.

While some of the aforementioned strategies have generated effective improvements in overall culture performance, many of these experimental assessments focus on monitoring culture parameters such as cell growth, biomass productivity, and the distribution of the main biomass fractions rather than on the physiological and regulatory responses triggered by each growth condition. Furthermore, the impact of the evaluated scenarios including the photosynthetic performance and the adaptation in terms of the lipidome distribution has not been integrally investigated despite their importance for further optimization. One additional factor to bear in mind is that there exists remarkable variability among the reported values of productivity and lipid content even for the same species (Metzger and Largeau 1999, 2005), perhaps due to the use of different protocols for analysis and standard culture conditions (Muzika et al. 2015).

We therefore investigated the metabolic responses of $B$. braunii LB 572 (Race A) in terms of photosynthetic performance and biomass and lipid productivity under a set of nutritional sufficiency and limitation settings. Additionally, we performed for the first time a comparative lipidomic analysis of $B$. braunii cells cultivated under diverse nutritional scenarios aiming to unveil to what extent the environmental conditions triggered changes in the lipid profiles of this strain and consequently, on its suitability for further bioenergy valorization.

\section{Materials and methods}

\section{Strain and standard maintenance culture conditions}

Botryococcus braunii LB 572 (Chlorophyta, Trebouxiophyceae) was obtained from the UTEX algae culture collection. For inoculum production and maintenance, the cells were cultivated in $500 \mathrm{~mL}$ conical flasks at $110 \mathrm{rpm}$ and continuously illuminated with cool white (RGB) LED lamps $\left(50 \mu \mathrm{mol}\right.$ photons $\left.\mathrm{m}^{-2} \mathrm{~s}^{-1}\right)$. Modified $\mathrm{BG}_{11}$ medium was used according to the following composition: $\mathrm{NaNO}_{3} 1 \mathrm{~g}$ $\mathrm{L}^{-1} ; \mathrm{MgSO}_{4} .7 \mathrm{H}_{2} \mathrm{O} 0.075 \mathrm{~g} \mathrm{~L}^{-1} ; \mathrm{CaCl}_{2} .2 \mathrm{H}_{2} \mathrm{O} 0.036 \mathrm{~g} \mathrm{~L}^{-1}$; $\mathrm{K}_{2} \mathrm{HPO}_{4} 0.093 \mathrm{~g} \mathrm{~L}^{-1} ; \mathrm{FeSO}_{4} 0.0034 \mathrm{~g} \mathrm{~L}^{-1}$; EDTA $0.001 \mathrm{~g}$ 
$\mathrm{L}^{-1} ; \mathrm{H}_{3} \mathrm{BO}_{3} 0.0028 \mathrm{~g} \mathrm{~L}^{-1} ; \mathrm{MnSO}_{4} \cdot \mathrm{H}_{2} \mathrm{O} 0.0018 \mathrm{~g} \mathrm{~L}^{-1}$; $\mathrm{ZnSO}_{4} .7 \mathrm{H}_{2} \mathrm{O} 0.22 \mathrm{mg} \mathrm{L}^{-1} ; \mathrm{Na}_{2} \mathrm{MoO}_{4} \cdot 2 \mathrm{H}_{2} \mathrm{O} 0.39 \mathrm{mg} \mathrm{L}^{-1}$; $\mathrm{CuSO}_{4} \cdot 7 \mathrm{H}_{2} \mathrm{O} 0.08 \mathrm{mg} \mathrm{L}^{-1} ; \mathrm{CoCl}_{2} \cdot 6 \mathrm{H}_{2} \mathrm{O} 0.04 \mathrm{mg} \mathrm{L}^{-1}$. Stock solutions, media preparation, and sterilization were made using the procedure suggested by the UTEX Culture Collection (U.S.A) as a reference. All reagents were of analytical grade and acquired from Sigma-Aldrich. The carbon source was supplied on a daily basis as 30-s pulses every $24 \mathrm{~h}$ of pure $\mathrm{CO}_{2}$ which was filtered through a $0.22-\mu \mathrm{m}$ PTFE membrane and injected into the cell suspension at $0.5 \mathrm{~L} \mathrm{~min}^{-1}$. The temperature was not controlled but remained constant between 24 and $26^{\circ} \mathrm{C}$.

\section{Evaluation of nutritional schemes}

Botryococcus braunii cells were first cultivated under standard maintenance conditions (see "Strain and standard maintenance culture conditions" section) until the cell concentration reached $1.5 \mathrm{~g} \mathrm{~L}^{-1}$. To this end, the cells were first washed three times by centrifugation $(20,000 \times g, 5 \mathrm{~min})$, followed by resuspension in medium without added nitrogen $(\mathrm{N})$ nor phosphorus $(\mathrm{P})$ under aseptic conditions. The washed cell suspensions were transferred to an approximate initial cell concentration of $0.4 \mathrm{~g} \mathrm{~L}^{-1}$ in maintenance media (see "Strain and standard maintenance culture conditions" section) with the modifications in nutrient composition and carbon supply described in Table 1.

For cultures supplemented with bicarbonate, suitable aliquots of $\mathrm{BG}_{11}$ nutrient stock solutions were mixed with the desired amounts of solid $\mathrm{NaHCO}_{3}$; and once the final volume was adjusted with deionized water, the media was filtered $(0.22-\mu \mathrm{m}$ Millipore cellulose membrane) under aseptic conditions. The cultures fed with $\mathrm{NaHCO}_{3}$ as the sole carbon source were daily sparged with $\mathrm{N}_{2}$ to decrease the level of dissolved oxygen evolved from photosynthetic

Table 1 Media composition and culture conditions evaluated for Botryococcus braunii LB 572

\begin{tabular}{ll}
\hline Condition ID & Media composition and culture conditions \\
\hline $\mathrm{NaHCO}_{3}{ }^{*} 0.1$ & $1 \mathrm{~g} \mathrm{~L}^{-1}-\mathrm{NaHCO}_{3}(0.1 \%)$ \\
$\mathrm{NaHCO}_{3} 1$ & $10 \mathrm{~g} \mathrm{~L}^{-1}-\mathrm{NaHCO}_{3}(1 \%)$ \\
$\mathrm{NaHCO}_{3} 2$ & $20 \mathrm{~g} \mathrm{~L}^{-1}-\mathrm{NaHCO}_{3}(2 \%)$ \\
$\mathrm{ND}$ & Nitrogen deprived $+\mathrm{CO}_{2}^{\dagger}$ \\
$\mathrm{PD}$ & Phosphorous deprived $+\mathrm{CO}_{2}^{\dagger}$ \\
Control & $+\mathrm{CO}_{2}^{\dagger}$ \\
Control_low light & $+\mathrm{CO}_{2}$ and $\left(15 \mu \mathrm{mol} \mathrm{m}{ }^{-2} \mathrm{~s}^{-1}\right)^{\dagger}$ \\
\hline
\end{tabular}

*All cellular suspensions used $\mathrm{BG}_{11}$ as the basal medium and were exposed to the same maintenance culture conditions described in the "Strain and standard maintenance culture conditions" section

${ }^{\dagger}$ Cultures fed with $\mathrm{CO}_{2}$ were daily sparged with 30-s pulses of membrane-sterilized pure gas as described in the "Strain and standard maintenance culture conditions"section activity. Each culture was sampled after 6 (D6) and 12 (D12) days of incubation to measure growth, nutrient concentration, photosynthetic parameters, and metabolite production. Each treatment was evaluated by triplicate.

\section{Analysis of nutrient consumption}

For nutrient consumption, each culture was sampled and centrifuged $(20,000 \times g, 5 \mathrm{~min})$. The $\mathrm{N}$ and $\mathrm{P}$ content remaining in the cell free supernatant were analyzed spectrophotometrically via the salicylic acid method and ascorbic acid method, respectively, as described elsewhere (Giraldo et al. 2020).

\section{In vivo chlorophyll a fluorescence measurement}

The photosynthetic performance was assessed by measuring the in vivo chlorophyll $a$ fluorescence using a Pulse Amplitude Modulation Fluorometer (Junior PAM. Walz GmbH, Germany). All measurements were performed after $20 \mathrm{~min}$ of dark exposure in microalgal samples taken directly from the culture. The maximal quantum yield of photochemical energy conversion in the photosystem II (PSII) was determined with dark adapted cells as follows: $F_{v} / F_{m}=\left(F_{m}-F_{0}\right) / F_{m}$, where $\mathrm{F}_{0}$ is the minimum level of fluorescence emitted due to the exposure to measuring light, and $\mathrm{F}_{\mathrm{m}}$ is the maximal fluorescence obtained with a short pulse of high irradiance actinic light $\left(10,000 \mu \mathrm{mol}\right.$ photons $\left.\mathrm{m}^{-2} \mathrm{~s}^{-1}\right)$. In order to assess the cell response and adaptation to different levels of irradiance under different nutrient configurations, rapid light curves (RLC) were constructed according to Malapascua et al. (2014). The effective quantum yield of PSII ( $\left.\mathrm{Y}_{\text {II }}\right)$ was determined under different actinic light (30-s exposure) levels as $Y_{I I}=\left(F_{m}-F\right) / F_{m}$, that is equivalent to $\Delta F / F_{m}$ or $\Phi_{\mathrm{II}}$, where $F_{m}$ is the maximal fluorescence in light induced by a saturating pulse, and $F$ the fluorescence under actinic light. $Y_{I I}$ was used to calculate the relative electron transport rate of PSII as $r E T R\left[\mu\right.$ mol electrons $\left.m^{-2} s^{-1}\right]=Y_{I I} \times E_{P A R}$, where $E_{P A R}$ is the incident irradiance of PAR (photosynthetically active radiation, $\lambda=400-700 \mathrm{~nm}$ ) light.

\section{Lipid extraction and quantification}

Total lipid content in the biomass was estimated gravimetrically. The cell suspensions were concentrated by centrifugation $\left(20,000 \times g, 5 \mathrm{~min} ., 4^{\circ} \mathrm{C}\right)$ and rinsed twice with deionized water. The concentrated cell pellet was finely ground with liquid nitrogen (mortar and pestle). The treated biomass was then mixed with $10 \mathrm{~mL}$ of hexane:isopropanol (3:1), homogenized by vortexing and centrifuged $(20,000 \times g$, 5 min, $4{ }^{\circ} \mathrm{C}$ ). The supernatant containing the lipophilic extract was transferred to a glass vial, and the extraction procedure was repeated twice using the residual biomass. 

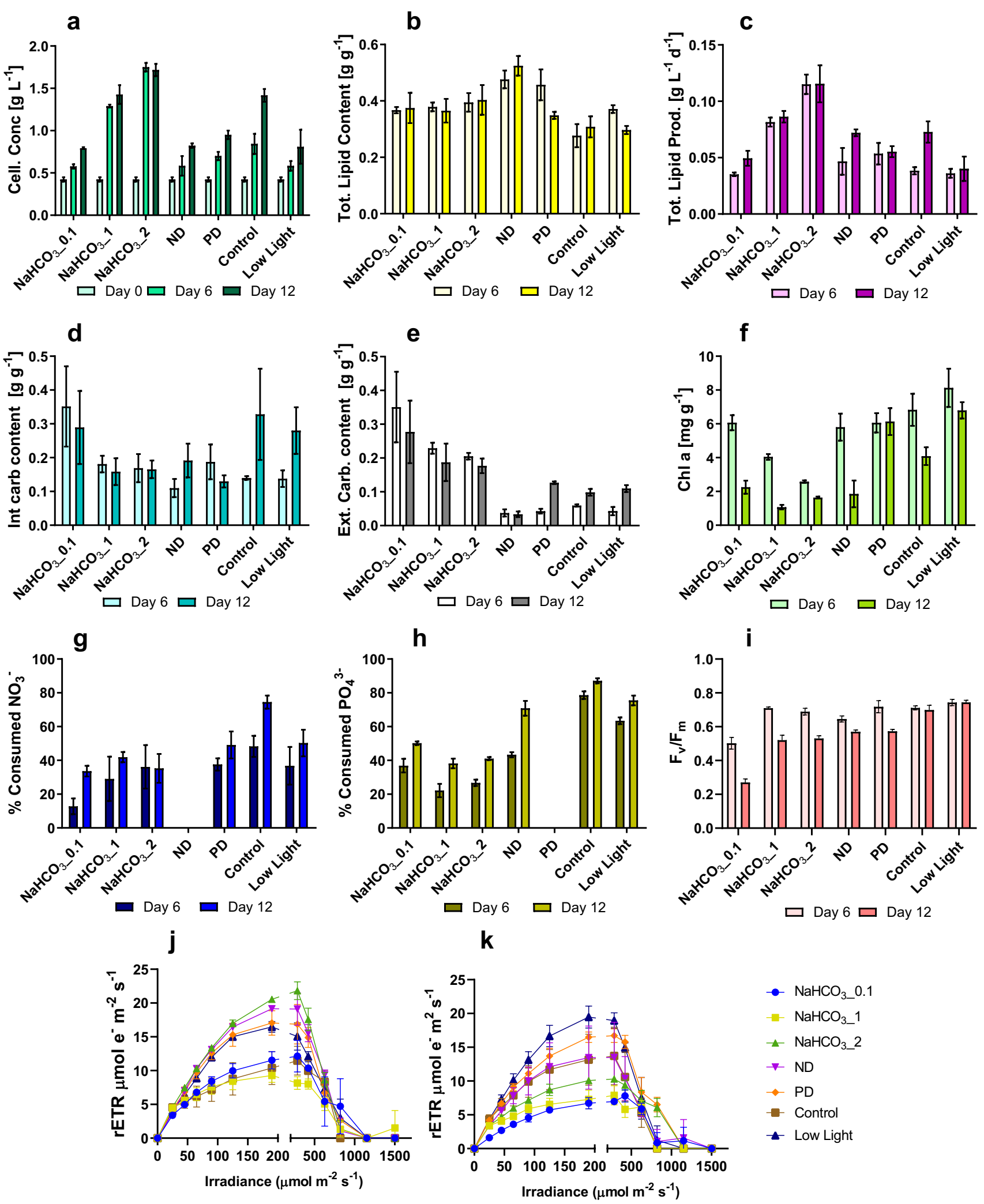

- $\mathrm{NaHCO}_{3} 0.1$

- $\mathrm{NaHCO}_{3-1}$

$₫ \mathrm{NaHCO}_{3} 2$

$\checkmark \mathrm{ND}$

$\leftrightarrow$ PD

- Control

- Low Light 
४Fig. 1 Culture parameters of Botryococcus braunii LB 572 measured at 6 and 12 days of incubation under different conditions. (a) Biomass concentration expressed as dry weight. (b) Total lipid content. (c) Total lipid productivity. (d) Intracellular carbohydrates content. (e) Extracellular carbohydrates to biomass ratio. (f) Chlorophyll $a$ content. (g) Percentage of consumed nitrate. (h) Percentage of consumed phosphate. (i) Maximum quantum yield of PSII photochemistry. (j, k) Rapid light curves constructed at D6 and D12, respectively for the relative electron transport rate (rETR) expressed in $\mu$ mol electrons $\mathrm{m}^{-2} \mathrm{~s}^{-1}$ versus irradiance of photosynthetic active radiation (PAR) expressed as $\mu \mathrm{mol}$ photons $\mathrm{m}^{-2} \mathrm{~s}^{-1}$. Data shown are means \pm SD from three independent replicates

The lipophilic extracts were recovered and dried in a rotatory evaporator (Buchi R215). The total lipid content was calculated as the ratio between the weight of the dry lipophilic extract and the total biomass used for the extraction.

\section{Lipidomic analysis and statistical analyses}

The lipidome analysis was performed by UPLC-MS (Acquity UPLC System) for the total lipid fraction of biomass samples taken at D6 and D12, according to the procedure published by Bromke et al., (2015). The mass spectra were acquired using an Orbitrap mass spectrometer and were processed with the Refiner MS 7.5 (Genedata Expressionist) and Xcalibur software. The validation of the lipids identified was made by comparison with an in-house library. The output contained a list of features associated with the intensities of peaks. Features naturally containing the heavy carbon isotope $\left({ }^{13} \mathrm{C}\right)$ were removed from the data set. The output data was normalized to the amount of sample used for the analysis. For the statistical analysis, the webserver MetaboAnalyst (Chong et al. 2019) was used. The data were auto-scaled and normalized. Significant differences were determined by performing a Kruskal Wallis test (Chong et al. 2019). To visually explore differences in the distribution of lipid profiles among nutritional schemes, a principal component analysis (PCA) was carried out. To further investigate the patterns of the lipid species that changed across the groups of samples, heatmaps and bar plots were built based on the calculated lipid ratios among the cells subjected to the nutritional schemes and the control samples.

\section{Carbohydrate extraction and quantification}

For total intracellular carbohydrates (in-CHOs) quantification, the defatted biomass residue was weighted and boiled with deionized water for $10 \mathrm{~min}$. The dissolved in-CHOs were then separated from the biomass pellet by centrifugation $(15.000 \times g, 10 \mathrm{~min}$.). The total in-CHOs concentration was determined following the phenol/sulfuric acid method of Masuko et al. (2005). To estimate the extracellular dissolved CHOs (ex-CHOs), the centrifuged cell-free supernatant of each culture was also analyzed via the phenol/sulfuric acid method.

\section{Chlorophyll extraction and quantification}

Fresh biomass samples were extracted with DMSO, and the chlorophyll $a$ content was spectrophotometrically determined according to the method of Griffiths et al. (2011).

\section{Statistical analyses}

All data measurements are shown as the mean \pm standard deviation $( \pm \mathrm{SD})$ of three independent replicates. Statistical analyses were performed in Prism 8 (GraphPad, USA). The results were analyzed by one-way or two-way analyses of variance (ANOVA), and the means of the treatments were compared by Tukey's multiple comparison test. In all analyses, $P<0.05$ was considered as significant. Brown-Forsythe test was performed to evaluate differences between SDs, and Shaphiro-Wilk or Kolmogorov-Smirnov tests were used to assess the normal distribution of the data.

\section{Results}

\section{Cell growth}

Botryococcus braunii LB 572 cells were cultivated under different nutritional schemes of sufficiency or limitation aiming to identify metabolic responses at the level of photosynthetic performance, biomass productivity, and composition. Under all tested settings $B$. braunii exhibited differential growth trends (ANOVA, $F_{(6,14)}=103.2, P<0.0001$ ). The biomass production increased along with higher inorganic carbon availability, as can be observed from Fig. 1a, where the highest biomass concentrations were observed in cultures supplemented with 1 and $2 \%$ of $\mathrm{NaHCO}_{3}$, compared to all other groups at D6 and 12. On the other hand, cultures with $0.1 \% \mathrm{NaHCO}_{3}$ and cells incubated upon $\mathrm{N}$ - and P-deprivation, hereinafter referred to as ND and PD, respectively, showed a reduced growth and biomass production, compared to the control cultures $(P<0.0001$ for both treatments), and to the cells fed with 1 and $2 \% \mathrm{NaHCO}_{3}(P<0.0001$ for both treatments) (Fig. 1a).

\section{Effect of nutritional schemes on differential biomass composition}

The nutritional conditions under which $B$. braunii cells were grown, exerted a differential effect on the distribution of the biomass components measured. The total lipid 
content of ND cells at D12 was the highest among all treatments $(52 \% \pm 3.1 \%)$ (ANOVA, $\left.F_{(6,14)}=18.74, P<0.05\right)$, whereas the control samples accumulated $31 \% \pm 4.1 \%$ (Fig. 1b). Nevertheless, the highest lipid productivity was measured in cultures fed with the highest bicarbonate concentration (Fig. 1c). The total lipid content of PD cells at D6 $(45.7 \% \pm 5.5 \%)$ was larger compared to the control $(P<0.0001)$ and reached similar levels to $\mathrm{N}$-deprived cells $(P=0.0037)$; however, at D12 it was significantly reduced to a value close to the control $(35.2 \% \pm 1.2 \%)(P=0.7961)$ (Fig. 1b). We also highlight that the lipid productivity remained almost unchanged between D6 and D12 in the cultures supplied with 1 and $2 \% \mathrm{NaHCO}_{3}$ and in the PD cells (Fig. 1c).

Similarly, the CHOs production also displayed distinct responses across the groups. The highest total in-CHOs were found in the cultures fed with the lowest $\mathrm{NaHCO}_{3}$ levels and the controls at D12 (Fig. 1d) (ANOVA, $F_{(6,14)}=5.483$, $P=0.0042)$. Alternatively, the highest ex-CHOs concentrations were measured in cells grown on $\mathrm{NaHCO}_{3}$ (ANOVA, $F_{(6,14)}=35.60, P<0.0001$ ) (Fig. 1e). The ex-CHOs production relative to biomass was slightly more sensitive to $\mathrm{P}$ deprivation since their concentration in PD cultures increased from $0.042 \pm 0.007$ to $0.127 \pm 0.004 \mathrm{~g} \mathrm{~g}^{-1}$ in the time lapse between D6 and D12, whereas it remained around $0.03 \pm 0.01 \mathrm{~g} \mathrm{~g}^{-1}$ for ND cultures (Fig. 1e).

There was a reduction in chlorophyll content between D6 and D12 (ANOVA, $F_{(1,14)}=139.3, P<0.0001$ ) for most of the nutritional schemes. Conversely, it remained constant for the PD cultures $(P>0.99)$ (Fig. 1f). Additionally, the lowest chlorophyll content was obtained at D12 in cultures supplied with $1 \% \mathrm{NaHCO}_{3}\left(1.07 \pm 0.13 \mathrm{mg} \mathrm{g}^{-1}\right)$.

\section{Photosynthesis performance}

We assessed the influence of different nutritional sufficiency or limitation schemes on the photosynthetic performance of $B$. braunii and its relationship with biomass production and metabolite accumulation. First, we compared the maximum quantum yield of PSII photochemistry $\left(F_{v} / F_{m}\right)$ for all conditions at D6 and D12 (Fig. 1i). At D6, the $F_{v} / F_{m}$ was not substantially different across most of the tested conditions $(P>0.05)$, except for the culture with $0.1 \% \mathrm{NaHCO}_{3}$ that was considerably lower $(P<0.001)$. In contrast, at D12, there was a generalized reduction in $F_{v} / F_{m}(0.487-0.585)$ across the groups, although it remained unchanged around 0.7 for the control cultures.

Additionally, we constructed RLC from dark adapted cells to further investigate the effect of the tested conditions on $B$. braunii photochemical energy conversion capacity and to get insights about its tolerance against high doses of irradiance. The results indicated that the cultures with $2 \% \mathrm{NaHCO}_{3}$ showed the highest productivity (rETR) at D6
(ANOVA, $F_{(3.69,95.96)}=67.50, P<0.0001$ ), followed by ND and PD cells (Fig. 1j). However, whereas this parameter remained constant for PD cells at D12, a significant reduction was observed either for $\mathrm{ND}, 0.1 \%-\mathrm{NaHCO}_{3}$ and more drastically for $2 \%-\mathrm{NaHCO}_{3}$ treatments (Fig. $1 \mathrm{k}$ ), which is consistent with the changes observed in biomass production (Fig. 1a) and chlorophyll content (Fig. 1f). Furthermore, it was also observed that the rETR increased for the control cultures from D6 to D12, whereas it did not display substantial changes for $1 \% \mathrm{NaHCO}_{3}$ (Fig. 1j, k).

In general, the maximal rETR observed in this study was reached between 200 and $300 \mu$ mol photons $\mathrm{m}^{-2} \mathrm{~s}^{-1}$. At about $400 \mu \mathrm{mol}$ photons $\mathrm{m}^{-2} \mathrm{~s}^{-1}$, a progressive decline in rETR was detected, reaching values close to zero. When the photon flux density exceeded $1250 \mu \mathrm{mol}$ photons $\mathrm{m}^{-2} \mathrm{~s}^{-1}$, photoinhibition was evident as a clear decline in photosynthetic activity upon such high irradiance.

In addition to the aforementioned measurements, we also performed a quenching analysis based on the estimation of photochemical and non-photochemical quenching in terms of the energy absorbed by the cells. The comparison of photosynthetic parameters upon $\mathrm{NaHCO}_{3}$ supply indicated that at D6, an increased dose of the carbon source provoked an increase in the values of $\mathrm{Y}_{\mathrm{II}}$ (Fig. 2a) and a decline in the level of the $\mathrm{Y}_{\mathrm{NO}}$ (Fig. 2c). On the other hand, the $\mathrm{Y}_{\mathrm{NPQ}}$ was similar within all carbon concentrations $(P>0.05)$ during the same period of time (Fig. 2e). By D12, the most significant difference was observed in $0.1 \% \mathrm{NaHCO}_{3}$ where there was a drastic increment of $\mathrm{Y}_{\mathrm{NO}}$ at expenses of an equivalent drop in the $\mathrm{Y}_{\mathrm{II}}$ and more notably in $\mathrm{Y}_{\mathrm{NPQ}}$.

For ND cells, the $\mathrm{Y}_{\mathrm{II}}$ was higher than the control when the cells were exposed at D6 to lower irradiances (25-285 $\mu \mathrm{mol}$ photons $\mathrm{m}^{-2} \mathrm{~s}^{-1}$ ) (Fig. 2b), in contrast to the $\mathrm{Y}_{\mathrm{NPQ}}$, which was significantly lower than the control $(P<0.01)$ for most of the tested light levels. Thereafter, the $\mathrm{Y}_{\mathrm{NPQ}}$ increased at D12 as a consequence of the photoprotection mechanisms activated during the prolonged $\mathrm{N}$ shortage (Pessarakli 2016).

$P$ deprivation on the other hand, had a significant effect on the activation of photoprotective mechanisms since PD cells had the lowest $Y_{\mathrm{NO}}$ (Fig. 3d) and highest $Y_{\mathrm{NPQ}}$ (Fig. 3f) among all treatments $(P<0.05)$ for irradiances above $285 \mu \mathrm{mol}$ photons $\mathrm{m}^{2} \mathrm{~s}^{-1}$.

\section{Comparative lipidomics analysis under different nutritional schemes}

We performed a UPLC-MS-based lipidomics profiling to depict the differential impact of several nutritional schemes on $B$. braunii neutral lipids biosynthesis and structural lipids remodeling. We identified lipid species classified 

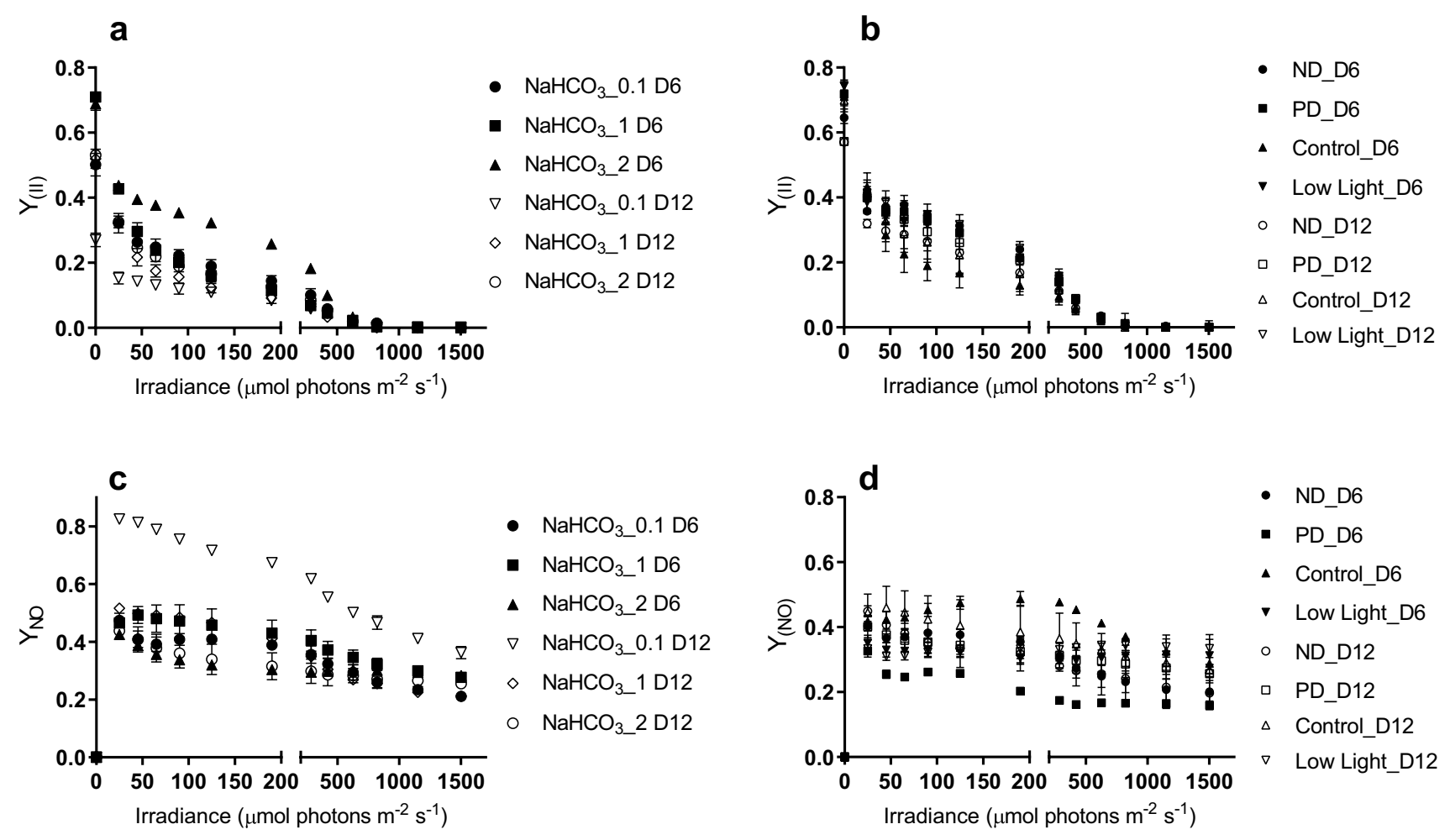

e

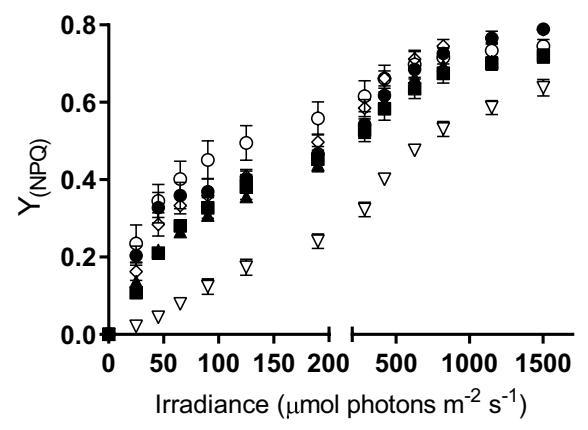

Fig. 2 Photochemical and non-photochemical quenching light curves of $B$. braunii constructed at days 6 and 12 of incubation under different nutritional conditions. (a, b) Effective quantum yield of PSII photochemical quenching. (c, d) Quantum yield of the energyindependent photochemical quenching. (e, f) Quantum yield of the energy-dependent photochemical quenching. Plots on the left side

into several lipid classes, namely diacylglycerol (DAG), digalactosyldiacylglycerol (DGDG), diacylglyceryl-N,N,Ntrimethylhomoserine (DGTS), monogalactosyldiacylglycerol (MGDG), phosphatidylcholine (PC), phosphatidylglycerol (PG), phosphatidylserine (PS), sulfoquinovosyldiacylglycerol (SQDG), and triacylglycerol (TAG). A PCA performed on all the aforementioned lipids, demonstrated that a high level of variation in the lipidome $(50.1 \%$ and $48.4 \%$, at D6 and D12, respectively) among groups can be explained by the first component (PC1; Fig. 3a-b). The PCA showed that

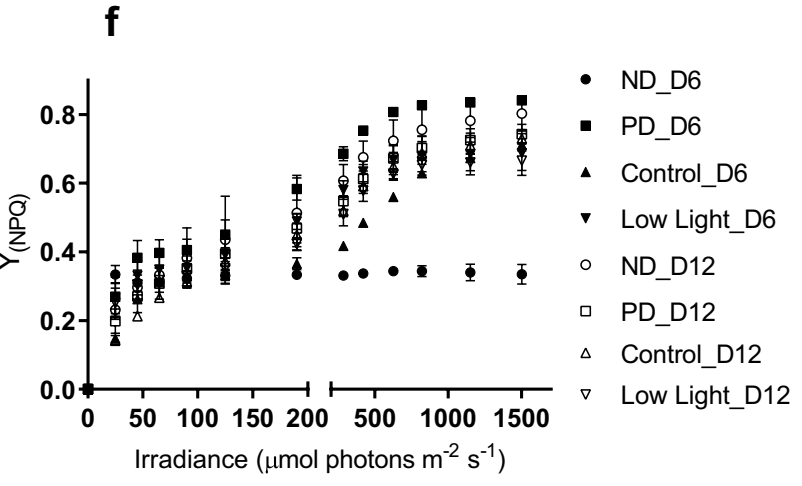

of the figure show data of cultures supplemented with bicarbonate whereas plots in the right correspond to ND, PD, and control cultures. The curves are constructed with dark adapted cells. Each point corresponds to the mean \pm SD computed from three independent replicates

the lipid composition of D6 samples differed to a greater extent in B. braunii under ND and PD conditions, and when the carbon source supplied was $1 \%$ and $2 \% \mathrm{NaHCO}_{3}$ (Fig. 3a). At D12, the lipid profiles remained significantly different for $B$. braunii fed with $1 \%$ and $2 \% \mathrm{NaHCO}_{3}$, while the profiles of ND and PD samples became closer to the control samples (Fig. 3b). This situation may be explained by the nutrient shortage experienced by control samples at the later stages of growth, while the cells grown under the 

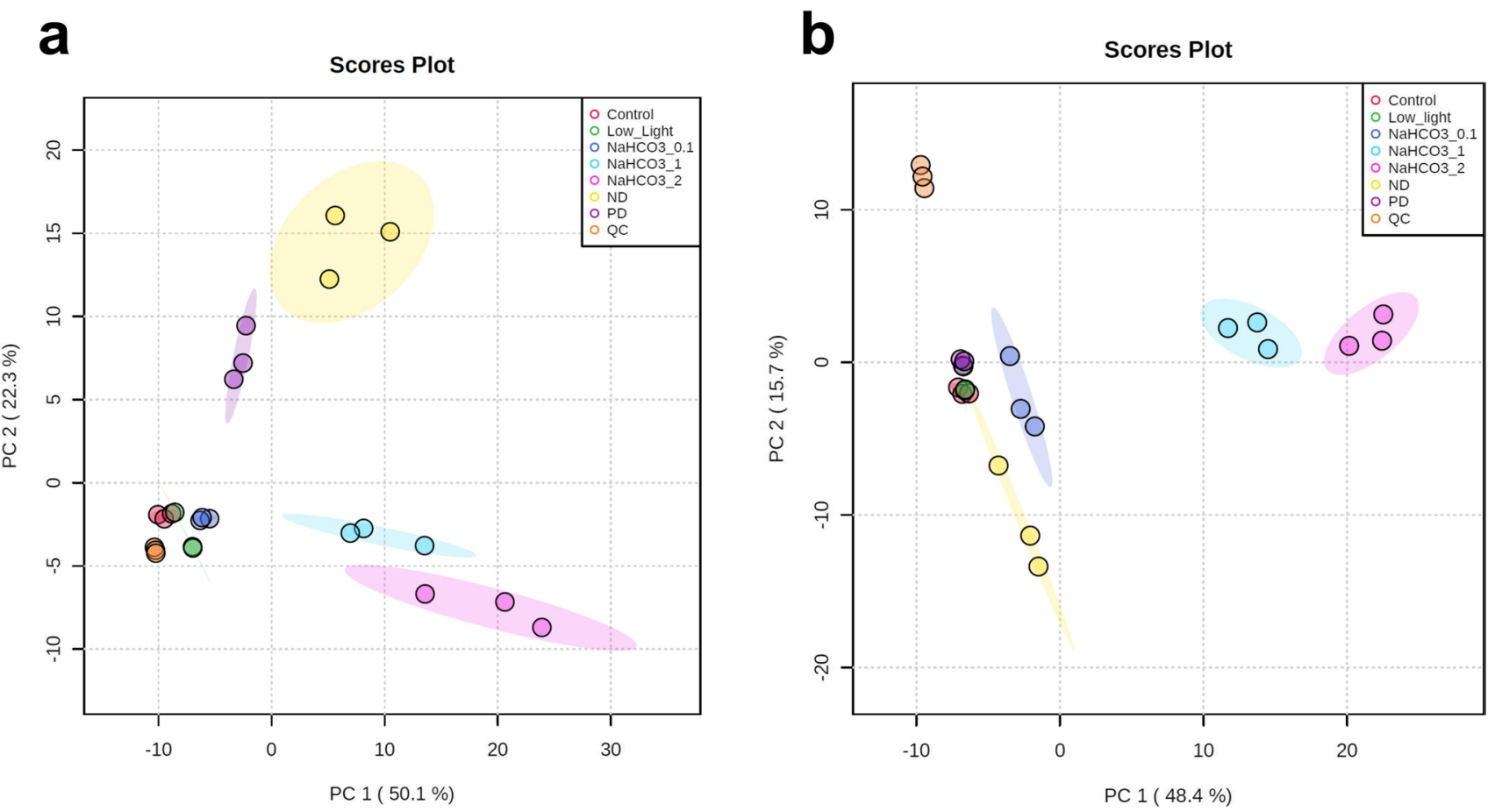

\section{C}

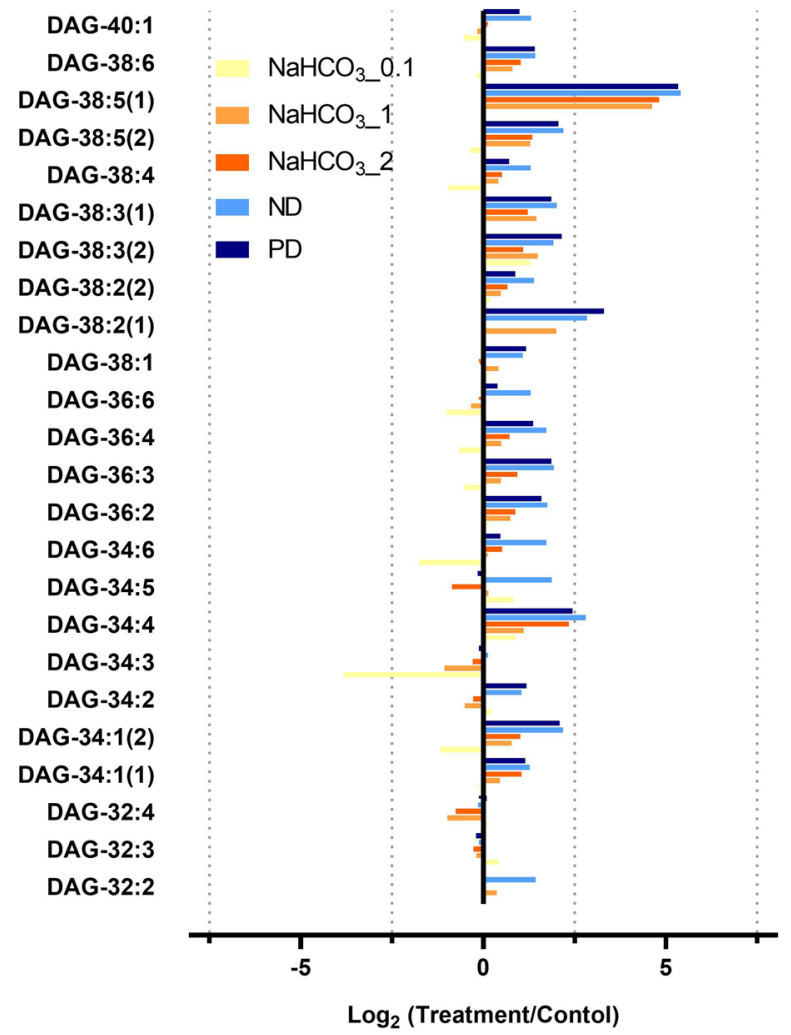

d

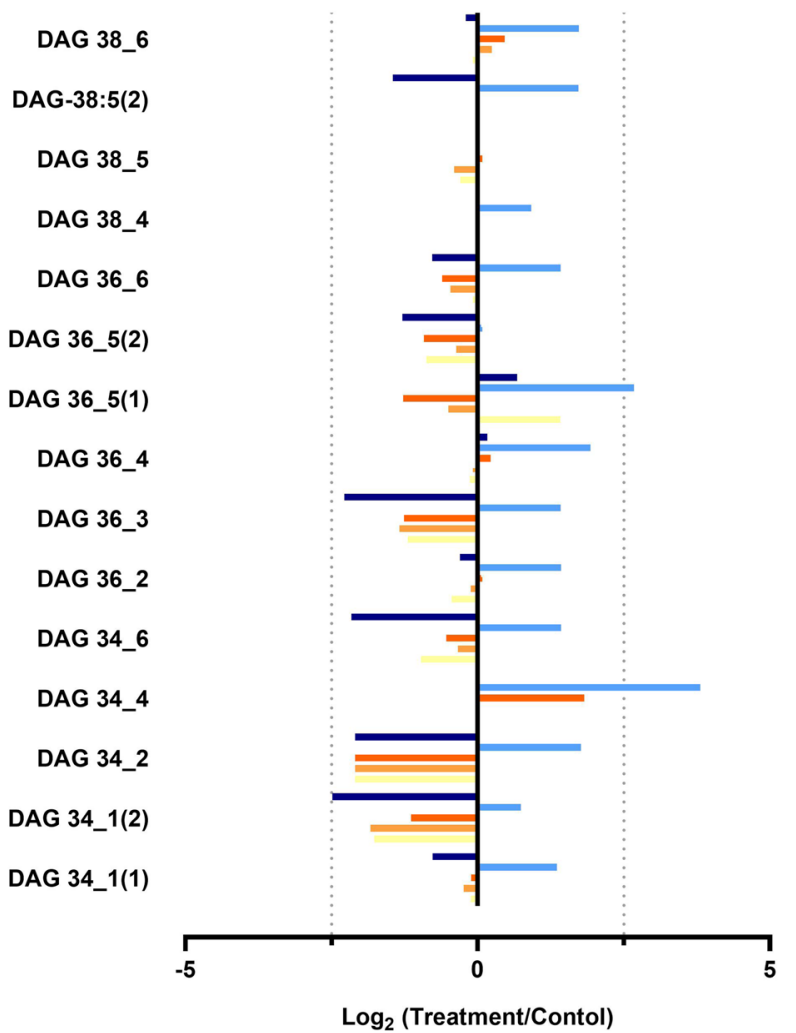


4Fig. 3 Principal component analysis (PCA) of B. braunii cells cultivated under different nutritional schemes at (a) day 6 (cumulative $72.4 \%$ of variation explained by the model) and (b) day 12 (cumulative $64.1 \%$ of variation explained by the model). The DAG distribution was further explored by calculating the $\log _{2}$ transformed lipid abundance ratios at (c) day 6 and (d) day 12, showing the most representative variations with respect to the control. The lipid species are identified by the abbreviation of the lipid class, followed by $\mathrm{C}: \mathrm{N}$, where $\mathrm{C}$ is the total number of carbons in acyl chains, and $\mathrm{N}$ is the total number of double bonds, which in some cases also includes a number in round brackets that indicate the isomers. DAG, diacylglycerol; ND, nitrogen-deprived medium; PD, phosphate-deprived medium

nutritional schemes with high $\mathrm{NaHCO}_{3}$ consumed the nutrients (i.e., $\mathrm{N}$ and $\mathrm{P}$ ) more efficiently (Fig. 1g, h).

\section{Effects of nitrogen deprivation in B. braunii lipidome}

After examining the abundance ratios for all the lipid species identified, we observed an overall increase for DAGs in the two time points evaluated (Fig. 3c, d). The major lipid constituents of the chloroplast membrane, corresponding to the galactolipids, DGDG and MGDG, were also examined (Fig. 4b, c). Over 60\% of the identified DGDGs were increased in the samples taken at D6 and D12 (Fig. 4b). On the contrary, the reduction of the abundance ratios predominated at D6 for the other chloroplast galactolipid, MGDG. A reduction of MGDGs was also observed at D12, but this was less pronounced than at D6 (Fig. 4c). The other chloroplast lipids that decreased at D12 were SQDGs, as well as the membrane glycerophospholipids (GPLs) PG, and PS (Fig. 5b), while the same species were under the detection limit at D6 (Fig. 5a). In addition, we also found that under N deprivation, several PC species were increased (Fig. 5b). A number of TAGs accumulated in both D6 and D12 samples (Fig. 4d), but the abundance ratios were in most cases higher at D6. These TAGs corresponded to molecules in which the sum of the carbon atoms of the fatty acyls ranged from 40 to 80 carbon atoms, and degree of unsaturation varying from fully and low unsaturated (1-2 unsaturations), to highly unsaturated (3-13). We also observed that the abundance of some TAGs was reduced (Fig. 4d), possibly as a result of TAG degradation (Li et al. 2014), although the acyl chain length and degree of unsaturation did not show a specific pattern. Besides the membrane glycolipids and GPLs, we also identified other structural lipids in B. braunii, namely DGTS, where the increase of several species occurred at D6 and D12 (Fig. 4a).

\section{Effects of phosphate deprivation in B. braunii lipidome}

We observed that under P deprivation, most of the DAGs increased at D6 while just a few species were reduced (Fig. 3c); however, a global reduction occurred for this lipid class when the cells were subjected to prolonged $\mathrm{P}$ deprivation
(D12) (Fig. 3d). We found a similar pattern for DGTS (Fig. 4a) and DGDG (Fig. 4b), but in this case, more species showed reductions in the abundance ratio at D6. In addition, we noticed a reduction of numerous MGDGs at early (D6) and late (D12) stages of culture (Fig. 4c). GPLs and SQDG were particularly reduced upon exposure of cells to prolonged $P$ deprivation (Fig. 5b). On the other hand, TAGs were predominantly accumulated at D6; however, after prolonged PD stress (D12), the magnitude of the TAGs abundance ratios dropped drastically, while a significant number may be degraded as suggested by the reduction trend (Fig. 4d).

\section{Lipidome remodeling of $B$. braunii cells grown under high carbon dosage}

When B. braunii cells were grown under different $\mathrm{NaHCO}_{3}$ regimes, a group of lipids increased or decreased concomitantly with the $\mathrm{NaHCO}_{3}$ concentration (Figs. 3c, d and 4a-d). At D6, we observed numerous DAGs that increased in $1 \%$ and $2 \% \mathrm{NaHCO}_{3}$ samples, while in cells grown on $0.1 \%$ $\mathrm{NaHCO}_{3}$, a majority of DAGs showed a reduced abundance (Fig. 3c). At D12, the trend was an overall DAG reduction independent of the $\mathrm{NaHCO}_{3}$ concentration (Fig. 3d).

Most of the chloroplast lipids DGDG and MGDG and the structural lipid DGTS increased at D6 (Fig. 4a-c), yet a significant number of species exhibited reduction in $0.1 \%$ $\mathrm{NaHCO}_{3}$ samples. At D12, the global trend of DGTS accumulation continued mostly in the cells grown on 1 and $2 \%$ $\mathrm{NaHCO}_{3}$ media, while the abundance ratio decreased in a considerable number of DGTS species in $0.1 \% \mathrm{NaHCO}_{3}$ cultures (Fig. 4a), alongside a high number of DGDGs and MGDGs in all samples (Fig. 4b, c). The DGDGs and MGDGs degraded at D6 in $0.1 \% \mathrm{NaHCO}_{3}$ samples were mainly polyunsaturated, and at D12 switched towards more saturated species. Several GPLs detected at D6 were reduced to some extent in $0.1 \% \mathrm{NaHCO}_{3}$ samples, while we noticed increased abundance for 1 and $2 \% \mathrm{NaHCO}_{3}$ (Fig. 5a). On the other hand, at D12, there were GPLs whose abundance ratios were increased or reduced, without showing a specific pattern related to the $\mathrm{NaHCO}_{3}$ concentration (Fig. 5b). The sulfolipids were under the detection limit at D6, nevertheless at D12, several SQDG species were detected, whose abundance was increased mostly in 1 and $2 \% \mathrm{NaHCO}_{3}$ samples (Fig. 5b).

TAGs on the other hand, displayed increased abundance ratios at D6 and D12 in 1 and $2 \% \mathrm{NaHCO}_{3}$ samples (Fig. $4 \mathrm{~d}$ ). In $0.1 \% \mathrm{NaHCO}_{3}$, the TAGs were also increased in the two time points evaluated, but the degradation pathways may be more active under this condition, particularly at D6, in view of a number of TAGs whose abundance ratios dropped. By comparing the TAGs distribution at D6, we found that $~ 76 \%$ of the identified TAGs were accumulated in the three $\mathrm{NaHCO}_{3}$ levels evaluated. This proportion rose to $92 \%$ in samples taken on D12. After making the same comparison 


\section{a}
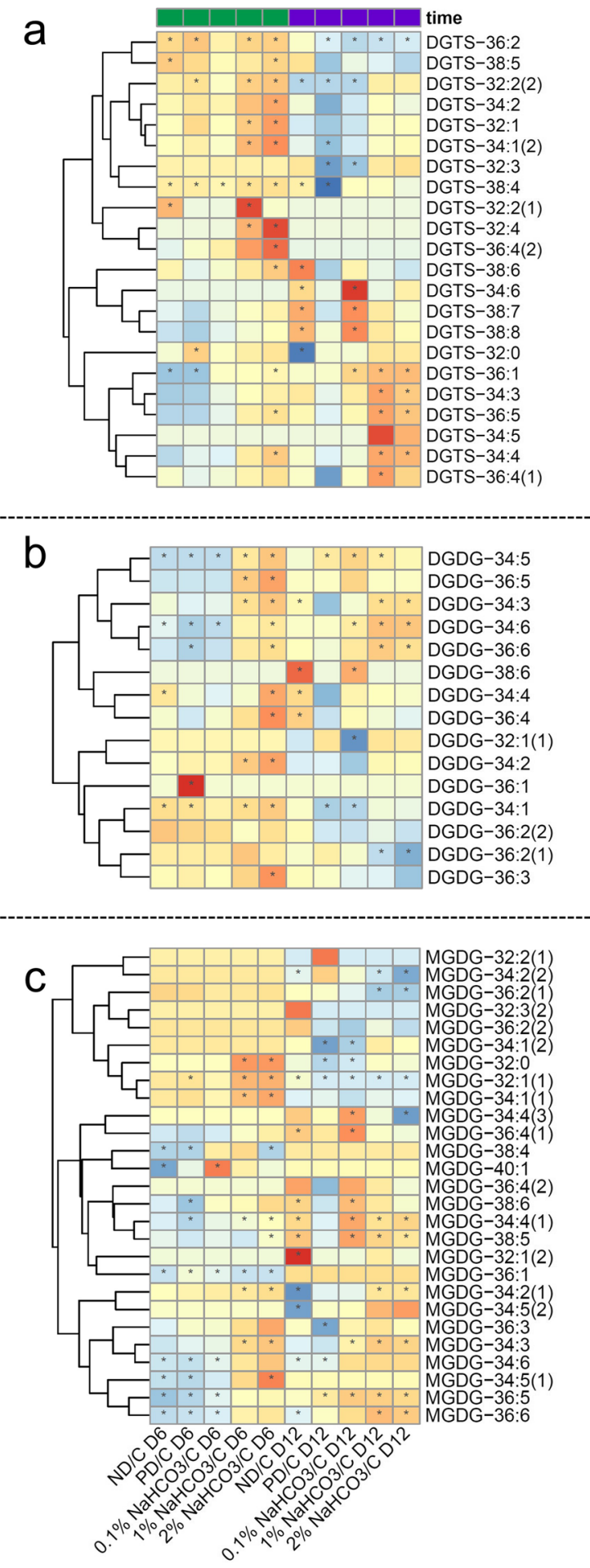

d

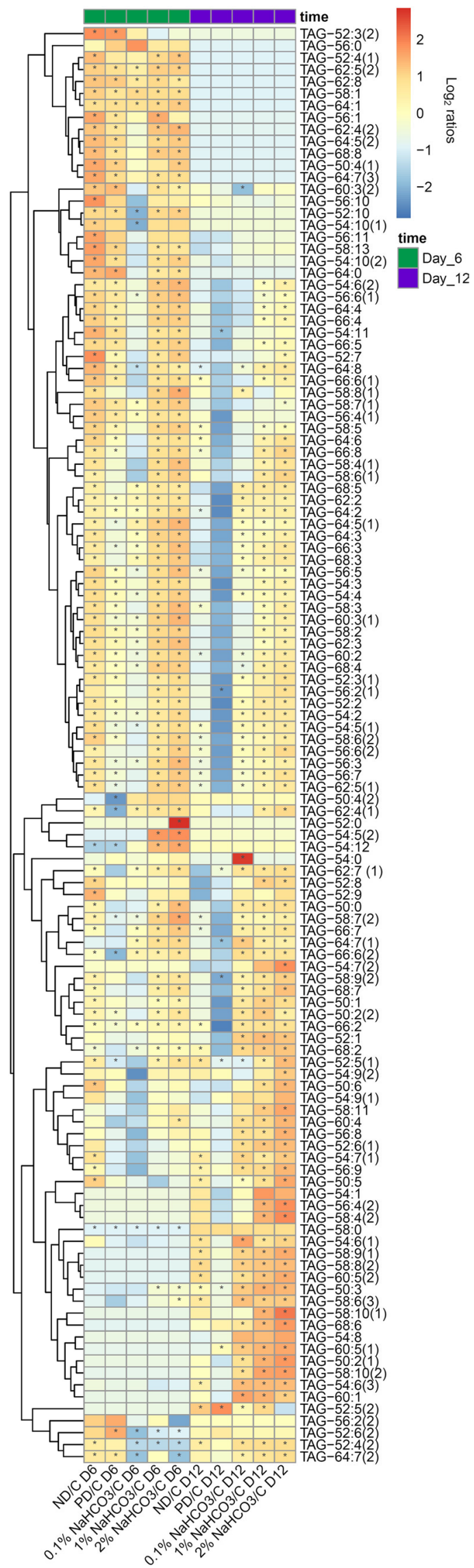


४Fig. 4 Heatmaps of the $\log _{2}$ transformed lipid abundance ratios of $B$. braunii cells grown under different nutritional schemes at day 6 (D6) and 12 (D12) showing structural lipids including (a) betaine lipids (i.e., DGTS) and the chloroplast lipids (b) DGDG and (c) MGDG; besides (d) the neutral lipids, i.e., TAGs, distributions. Further details of the TAGs distributions can be found in the supplementary material (Sup. 1). The lipid species are identified by the abbreviation of the lipid class, followed by $\mathrm{C}: \mathrm{N}$, where $\mathrm{C}$ is the total number of carbons in acyl chains and $\mathrm{N}$ is the total number of double bonds, which in some cases also includes a number in round brackets that indicate the isomers. The lipids with a higher-than three-fold change are marked with an asterisk. MGDG, monogalactosyldiacylglycerol; DGDG, digalactosyldiacylglycerol; DGTS, diacylglyceryl-N,N,N-trimethylhomoserine; TAG, triacylglycerol

but this time between samples taken at D6 and D12, we noticed that $75 \%$ of the identified TAGs were increased in the two sampling points. When examining the accumulated TAGs at the structural level (i.e., number of carbon atoms and degree of unsaturation), we did not identify a pattern that would indicate the accumulation of a specific group of TAGs, since there was a great variation in the length of the fatty acyls that made up the molecules, whose sum of their carbon atoms ranged between 40 and 80 , and with degree of unsaturation going from fully saturated up to 13 unsaturations.

Additionally, we compared the TAGs profile between the cells fed with $\mathrm{NaHCO}_{3}$ and the $\mathrm{N}$-deprived cultures. This time we found that $\sim 55 \%$ of the identified TAGs were accumulated in all samples of both nutritional schemes, and as in the previous case, we did not find a pattern that would indicate the preferential accumulation of a specific type of TAG. We also identified a group of TAGs that were exclusively accumulated in the samples taken at D6 of both nutritional schemes (e.g., TAG-40:0/-42:4/-50:4/-52:4/-56:0/-56:1/58:1/-62:4/-62:5/-62:8/-64:1/-64:5/-64:7/-68:8/-74:7/-78:4) of which $\sim 31 \%$ corresponded to lipids with a low degree of unsaturation ( $\leq 2$ unsaturations), while the remainder were polyunsaturated. At D12, we identified another group of TAGs (e.g., TAG-54:1/-56:4/-58:4/-58:10/-60:1/-60:5/$68: 6 /-70: 7 /-76: 3 /-76: 4 /-76: 8 /-80: 4)$ that was preferentially accumulated at this stage of the culture in which the proportion of polyunsaturated species was somewhat higher $(\sim 86 \%)$.

\section{Discussion}

\section{Cell growth}

In the present study, we observed that the carbon source and its concentration exerted an important influence on cell growth, which in the case of bicarbonate was in a concentration-dependent manner (Fig. 1a). The improved microalgal biomass yield in cultures supplied with rising levels of $\mathrm{NaHCO}_{3}$ has been previously reported and associated with the induction of carbon concentration mechanisms (CCM) (Vadlamani et al. 2019). These CCM serve as a mean to increase the flux of inorganic carbon from the extracellular medium into the chloroplast (Giordano et al. 2005). Part of the CCM relies on the expression of carbonic anhydrases that interconvert $\mathrm{CO}_{2}$ and $\mathrm{NaHCO}_{3}$ and whose $K_{\mathrm{m}}$ values are reported to be 10-20 mM (Mirjafari et al. 2007). Under standard cultivation conditions (i.e., low turbulence regimes and atmospheric $\mathrm{CO}_{2}$ levels), the carbon fixation rate and the underlying biomass production can be kinetically limited by substrate concentration at the carbon fixation site for RuBisCO, since the $K_{\mathrm{m}}\left(\mathrm{CO}_{2}\right)$ has been shown to be close to $30 \mu \mathrm{M}$ for green algae (Tcherkez et al. 2006). Therefore, high external carbon doses would help to compensate the low carbon availability at the fixation sites, particularly in the form of $\mathrm{NaHCO}_{3}$, which remains dissolved much longer than $\mathrm{CO}_{2}$. This in turn leads to a higher carbon fixation capacity, and the subsequent improvement of biomass productivity and yields.

$\mathrm{NaHCO}_{3}$ is commonly used as a carbon source in the growth media of the cyanobacterium Spirulina; nonetheless, it has not been extensively explored in microalgae with most research conducted using $\mathrm{CO}_{2}$ (Arun et al. 2020; Umetani et al. 2021); however, $\mathrm{NaHCO}_{3}$ has been recently considered as an alternative carbon feedstock for microalgae that improves biomass yield and also has proven to induce the accumulation of metabolites such as TAGs and carotenoids (Gardner et al. 2013). Moreover, Srinivasan et al. (2018) suggested that bicarbonate ions could also promote reactive oxygen species scavenging and biomass formation in algal cells even upon nutrient limitation conditions.

Remarkably, our results showed that $B$. braunii LB 572 not only can grow faster in the presence of high $\mathrm{NaHCO}_{3}$ levels (up to $2 \%$ ) but also, such conditions promoted sustained TAG accumulation (see "Lipidome remodeling of B. braunii cells grown under high carbon dosage" sections) without the need of a second stage of nutrient deprivation that is traditionally used for lipid accumulation in algal systems.

$\mathrm{N}$ - and P-deficiency conditions tested in this study were detrimental for $B$. braunii growth when compared with the control (Fig. 1a). $\mathrm{N}$ is a major constituent of biomass, forming part of a wide range of biomolecules such as nucleic acids, proteins, and cofactors. Moreover, $\mathrm{N}$ assimilation represents an important sink for reducing power, especially when the main $\mathrm{N}$ source supplied is an oxidized form such as $\mathrm{NO}_{3}{ }^{-}$(Grund et al. 2019). In that sense, low $\mathrm{N}$ availability implies a lower capacity of biomass formation (Bolton 2006). For instance, Zhila et al. (2005) found that B. braunii IPPAS H-252 cultures produced two times less biomass in a N-deprived media as compared to the controls. Similar outcomes have also been documented by other authors with different B. braunii strains (Lupi et al. 1994; Choi et al. 2011; Barajas-Solano et al., 2016) . On the other hand, P 
Fig. 5 Exploration of the GPLs and SLs distribution by calculating the $\log _{2}$ transformed lipid abundance ratios at (a) day 6 and (b) day 12 showing the most representative variations with respect to the control. The lipid species are identified by the abbreviation of the lipid class, followed by $\mathrm{C}: \mathrm{N}$, where $\mathrm{C}$ is the total number of carbons in acyl chains and $\mathrm{N}$ is the total number of double bonds, which in some cases also includes a number in round brackets that indicate the isomers. ND, nitrogen-deprived medium; PD, phosphate-deprived medium; PC, phosphatidylcholine; PG, phosphatidylglycerol; GPLs, phospholipids; PS, phosphatidylserine; SLs, sulfolipids; SQDG, sulfoquinovosyldiacylglycerol

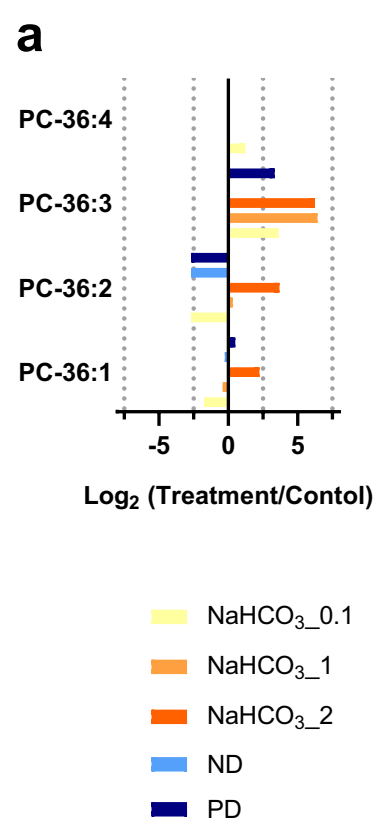

b

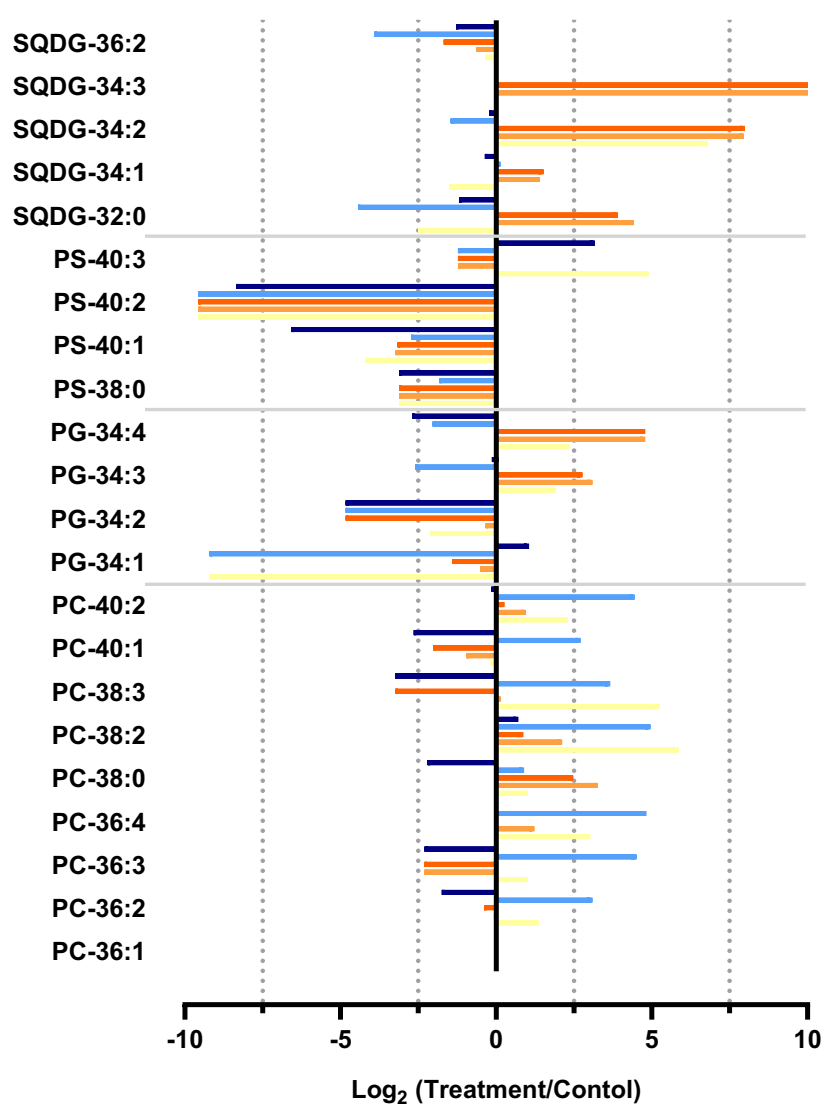

cells incubated with the highest $\mathrm{NaHCO}_{3}$ level when compared with the controls and nutrient-starved samples (Fig. 1c). This is due to the significantly greater biomass and therefore lipid productivity reached with the highest carbon dosages, even though their lipid content was somehow lower than the value measured for ND cells (Fig. 1b).

Moreover, the fact that the increased lipid productivity remained constant between D6 and D12 might result convenient from a process design perspective, since it would facilitate the operation of a continuous process for lipidrich biomass production and its subsequent transformation, rather than designing a two-stage system consisting of a cell growth phase, followed by a nutritional stress and lipid accumulation stage (Biller et al. 2015). Furthermore, it might help to improve systems such as the in situ milking proposed by some researchers (Hejazi and Wijffels 2004; Kleinert and Griehl 2020), where the basic concept relies on the continuous solvent-based lipid extraction, omitting the cellular disruption step.

Botryococcus braunii is also known for its capacity to produce and excrete polysaccharides originated from the internal fibrillar layer that play a crucial role as an adhesive matrix for colony formation and protection (Giraldo 
Calderón et al., 2018). These polysaccharides have been investigated for their wide range of applications in material science and microbiology (Navarro Gallón et al. 2019). In this study, we observed that ND and PD cultures had more similar amounts of in-CHOs compared to those in 1 and $2 \%$ $\mathrm{NaHCO}_{3}$ supplemented cultures, which might imply that this specific strain is prone to re-route the assimilated carbon towards more reduced and energetically dense molecules such as the lipids under certain nutritional scenarios. Some authors have suggested that CHOs production and excretion are associated with growth, while the highest yields are obtained at the final stages of the active growth, but also during the stationary and decline phases due to nutrient depletion (Blifernez-Klassen et al. 2018), as in the case of the control and PD cultures of our study (Fig. 1e). However, it is important to consider that the metabolic phenotypes are highly variable across $B$. braunii races, even for the same strain (Eroglu et al. 2011; Jin et al. 2016).

Some of the cultures underwent a substantial decrease in the Chl $a$ content among the two sampling points (Fig. 1f). In the case of the cultures amended with $\mathrm{NaHCO}_{3}$, this situation may have occurred due to a lower prevalence of light harvesting complexes associated with reduced requirements for passive non-photochemical energy dissipation upon high carbon availability (Pessarakli 2016). The results revealed that the $\mathrm{Y}_{\mathrm{NO}}$ was lower $(P<0.05)$ (Fig. 2c) and the $\mathrm{Y}_{\mathrm{NPQ}}$ higher $(P<0.05)$ (Fig. 2e) for $2 \% \mathrm{NaHCO}_{3}$ cells compared to the controls at most irradiance values, and even more compared to the culture with $0.1 \% \mathrm{NaHCO}_{3}$. Similarly, the $\mathrm{N}$-starved cultures displayed a significant decrease in Chl $a$ content between D6 and D12 (Fig. 1f) following a common trend found in the literature (Zhila et al. 2005; Jerez et al. 2016). This reduction could be related to the fact that the $\mathrm{Chl}$ $a$ is a N-rich molecule that could be degraded under $\mathrm{N}$ scarcity for recycling purposes, and its biosynthesis is also prone to be downregulated under such conditions (Hockin et al. 2012). In this regard, a proteomic analysis of Thalassiosira pseudonana (CCMP 1335) revealed that $\mathrm{N}$ deficiency conditions resulted in a 1.5- to 2.5 -fold decrease of the expression levels of five proteins involved in chlorophyll biosynthesis (Hockin et al. 2012).

The P-starved cultures were the less sensitive in terms of chlorophyll production (Fig. 1f) since the Chl $a$ content remained unaltered in PD cultures throughout the course of the experiment. A similar result was found by (Kamalanathan et al. 2016) with Chlamydomonas reinhardtii.

\section{Photosynthesis performance}

$F_{v}, F_{m}$ is considered as an indicator parameter of the level of photosynthetic stress and photoinhibition (Malapascua et al. 2014). During the first days of incubation, $F_{v} / F_{m}$ remained similar across most of the tested conditions with values close to 0.7 (Fig. 1i); this indicates that B. braunii was not undergoing a metabolic pressure that significantly affected its capacity to perform photosynthesis during the first stages of growth. Nevertheless, the lower $F_{\sqrt{ }} / F_{m}$ value measured for the $0.1 \% \mathrm{NaHCO}_{3}$ culture indicates that a limited carbon availability impairs the metabolic fitness. This may be attributed to the overproduction of reductive power that cannot be rapidly channeled to carbon fixation due to the low intracellular $\mathrm{CO}_{2}$ level. This overreduction could be detrimental for the reaction centers at the PSII and could provoke a decline in its photochemical quantum yield (Pessarakli 2016). In contrast, at D12, $F_{\sqrt{ }} / F_{m}$ remained high for the controls, while the values for the remainder of the conditions were diminished $(0.487-0.585)(P<0.001)$, probably due to the reduction in the cellular chlorophyll content (Fig. 1f), adding to the nutrient shortage effect in ND and PD cultures (Jerez et al. 2016).

Aiming to assess the influence of the different conditions over the irradiance tolerance and adaptation capacity, RLC were constructed to relate a series of irradiance levels and the derived rETR (Fig. 1j, k). At D6, the highest rETR were recorded for $2 \% \mathrm{NaHCO}_{3}$, which were also the cells with the fastest growth rate. Higher carbon availability could lead to increased electron consumption rates due to the prevalence of carboxylation reaction over oxygenation performed by RuBisCO, decreasing the energy losses by non-photochemical energy dissipation and favoring the photochemical conversion (Pessarakli 2016). A similar outcome with a green algae was reported by Vadlamani et al. (2019), as these authors found that elevated $\mathrm{NaHCO}_{3}$ concentrations benefit the biomass productivity and the photosynthetic performance of Chlorella sorokiniana. Furthermore, it has been reported that the response to bicarbonate is strain-specific, and the enhancement of the photosynthetic metabolism occurs only under certain concentration thresholds (Yeh et al. 2010; White et al. 2012).

Interestingly, the cultures exposed to nutrient limitation (i.e., ND and PD) exhibited relatively high photosynthesis production values either at D6 and D12, and ND cultures displayed only a slight decay at D12, although it remained even higher than the rETR of the control (Fig. 1j, k). The ND cultures also suffered a drastic decline of the Chl $a$ content (Fig. 1f), which might lead to smaller light-harvesting complexes (LHCs) and consequently reduced cellular light absorption capacity (Zhao et al. 2017; Giraldo et al. 2021). Accordingly, we hypothesize that this reduction in the light harvested per cell may diminish the inhibitory effects of high irradiance and alleviate at some extent the pressure over the reaction centers at the PSII (Maxwell et al. 1995; Neidhardt et al. 1998). This was supported by the decrease in the $Y_{(\mathrm{NPQ})}$ (Fig. 2e) at the expense of an increase in the $Y_{\text {(II) }}$ (Fig. 2a) that resulted in higher rETR values (Zhao et al. 2017). 
However, from a different perspective, the energy partition factor between the PSII and PSI would have suffered changes due to possible alterations in the LHCs structure, triggered by the reduction in $\mathrm{Chl} a$ content (Baker 2008; Hogewoning et al. 2012). In such scenario and taking into account the changes in the cellular light absorption properties, the electron transfer rate values should be more accurately expressed as the absolute ETR, which is estimated based on the absorptance and partition factor measurements (Malapascua et al. 2014); however, the determination of these parameters was beyond the scope of the present study.

In the case of PD cultures, the photosynthetic production was not significantly affected either at D6 or D12 (Fig. 1j, k). This outcome, together with the unaltered $\mathrm{Chl} a$ content (Fig. 1f), could be explained by the fact that $\mathrm{P}$ is not as essential as $\mathrm{N}$ for chlorophyll biosynthesis (Kamalanathan et al. 2015). Additionally, scarcity of extracellular P is not detrimental for the photosynthetic apparatus (Kamalanathan et al. 2016), probably due to the rapid accumulation of intracellular reservoirs of polyphosphate bodies prior the transfer of the cells to the P-free medium (Powell et al. 2009). Furthermore, the elevated lipid accumulation in PD cultures compared to the control would have stimulated the reductive power demand from the electron transport chain, causing the augmented $Y_{(I I)}$ that accounted for the higher rETR values (Fig. $1 \mathrm{j}-\mathrm{k}$ ).

Despite the differences found in the rETR values, which reflect the photosynthetic productivity, the overall response in terms of irradiance tolerance and inhibition was similar among all the tested conditions. The saturation point ranged between 200 and $300 \mu \mathrm{mol}$ photons $\mathrm{m}^{-2} \mathrm{~s}^{-1}$, and above $400 \mu \mathrm{mol}$ photons $\mathrm{m}^{-2} \mathrm{~s}^{-1}$ the decline in the rETR values denoted the photoinhibition region (Fig. 1j, k). Interestingly, Yoshimura et al. (2013) found a relationship between the irradiance and the temperature that affects the specific growth rate in B. braunii var Showa. In that case, the authors found that at $20{ }^{\circ} \mathrm{C}$, the growth is somewhat inhibited with irradiance levels above $350 \mu \mathrm{mol}$ photons $\mathrm{m}^{-2} \mathrm{~s}^{-1}$. Conversely, in a different study, the photosynthesis in $B$. braunii became saturated at $1000 \mu \mathrm{mol}$ photons $\mathrm{m}^{-2} \mathrm{~s}^{-1}$ of red light (Sakamoto et al. 2012). Nonetheless, the different wavelengths used in each study can partially account the discrepancies.

The quenching analysis revealed that the different nutritional contexts evaluated for $B$. braunii cells had a significant impact on the dissipation and use of light energy. The cellular response (i.e., high $\mathrm{Y}_{\mathrm{II}}$ and low $\mathrm{Y}_{\mathrm{NO}}$; Fig. 2a, c, respectively) under the highest $\mathrm{NaHCO}_{3}$ concentration could be a consequence of a combined effect between an enhanced capacity to use the reducing power through the carbon fixation pathway, pulling electrons from the electron transport chain, and a concomitant maintenance of a stable intra-thylakoidal $\mathrm{pH}$ gradient that keeps the $\mathrm{Y}_{\mathrm{NPQ}}$ (Fig. 2e) similar among the groups (Malapascua et al. 2014). At D12 in contrast, the $Y_{N O}$ (Fig. 2c) surpassed significantly the $Y_{I I}$ (Fig. 2a) and $\mathrm{Y}_{\mathrm{NPQ}}$ (Fig. 2e) in the culture with the lowest $\mathrm{NaHCO}_{3}$ concentration, showing the photosynthetic impairment derived from the unavailability of carbon as the main electron sink.

The $\mathrm{N}$ deprivation showed to have an important impact not only on the carbon distribution into the different biomass components but also on the energy partitioning. At D6, the prevalence of $Y_{\text {II }}$ (Fig. 2b) over $Y_{\mathrm{NPQ}}$ (Fig. 2f) in ND cultures compared to the controls suggests that such nutritional context favors the photochemical conversion of the absorbed energy and reduces the need for active photoprotective mechanisms. This outcome led us to hypothesize that a higher reductive power demand in the form of NADPH to sustain the elevated rates of lipid biosynthesis (Fig. 1b) may be pulling the absorbed energy into the electron transport chain, rather than dissipating the exitonic energy as heat or fluorescence. Alternatively, Figueroa et al. (2021) reported that the green alga Ulva rigida, exhibited higher ETR values under low nitrogen $(5 \mu \mathrm{M}$ nitrate) and carbon (380 ppm $\mathrm{CO}_{2}$ ) conditions compared to low nitrogen and high carbon ( $\left.700 \mathrm{ppm} \mathrm{CO}_{2}\right)$ conditions. This was explained due to the disturbance in the dynamics of the NADPH and ATP production for carbon assimilation and the changes in the $\mathrm{C}: \mathrm{N}$ ratio derived from the $\mathrm{N}$ reallocation inside the cells. At D12, the drastic reduction of Chl $a$ level, along with the prolonged $\mathrm{N}$ starvation, led to the stimulation of active photoprotection mechanisms expressed as $\mathrm{Y}_{\mathrm{NPQ}}$ (Fig. 2f) that resulted in the decline of the contribution of the $\mathrm{Y}_{\mathrm{II}}$ (Fig. 2b).

On the other hand, P starvation showed a substantial impact on the distribution among the passive and active energy dissipation mechanisms. During the first days of incubation, the contribution of the active photoprotective mechanisms (i.e., xanthophyll cycle) was more active than the passive dissipation of the energy surplus as heat (i.e., $\mathrm{Y}_{\mathrm{NO}}$ ) (Fig. 2d). Accordingly, P-deprived B. braunii cells could preferentially activate the energy-mediated photoprotection systems (Cui et al. 2017). The increase in $Y_{N P Q}$ (Fig. 2f) could serve as a mechanism to cope with the lightinduced stress and the accumulated proton motive force derived from the substrate-dependent limitation in the phosphorylation reactions and the limited carbon fixation rate, as similarly reported by (Wykoff et al. 1998). A comparative proteomic analysis performed with Karlodinium veneficum revealed a significant metabolic remodeling response under P starvation (Cui et al. 2017). These authors indicated that some of the most P-consuming processes (e.g., cell proliferation) were downregulated, while some energy-producing/ consuming metabolic pathways remained active or were even upregulated such as glycolysis, tricarboxylic acid cycle, 
and lipids metabolism. Additionally, the level of expression of several LHC-related proteins was increased upon P-deprivation, which explains the conservation of the photosynthetic activity observed under such conditions. Even though our results are consistent with those shown in the cited reports, the specific mechanism governing the energy distribution and its relationship with the lipid metabolism is a complex process which remains largely at the level of speculation for B. braunii and is open to be further experimentally explored.

\section{Effects of nitrogen deprivation in B. braunii lipidome}

$\mathrm{N}$-deprivation of microalgae triggers membrane lipid turnover and breakdown (Li et al. 2012; Simionato et al. 2013; Martin et al. 2014; Han et al. 2017; Kokabi et al. 2020) and de novo synthesis of fatty acids (FA) (Li et al. 2012; Kokabi et al. 2020), to supply precursors for TAG assembly. Lipid turnover and degradation under $\mathrm{N}$ deprivation is central to keep membrane homeostasis under stress, especially in chloroplasts, thus explaining the increase of DGDG to MGDG ratio, which corresponds to the major chloroplast lipids (Kobayashi 2016). This is in agreement with our observations of a major abundance of DGDG compared to MGDG species (Fig. 4b, c), and with results published by other authors ( $\mathrm{Li}$ et al. 2014; Han et al. 2017; White et al. 2019; Kokabi et al. 2020).

MGDG reduction under nutrient limitation is consistent with its role as the major thylakoid constituent and its function in the photosynthetic pigment-protein complexes (White et al. 2019). Therefore, the loss of cellular viability following $\mathrm{N}$-deprivation could be avoided by blocking photosynthetic electron transport or redirecting the exitonic energy through non-photochemical dissipation routes (Fig. 2f), relieving a detrimental overreduction of the photosynthetic electron transport chain ( $\mathrm{Li}$ et al. 2012). Hence, membrane lipids recycling into TAGs may represent a protective mechanism to minimize the destruction of the thylakoid and chloroplast envelope membranes (Han et al. 2017). DGDG increase, on the other hand, suggests a physiological adaptive response to nutrient stress for the functional and structural stabilization of the chloroplast (Han et al. 2017; White et al. 2019).

As mentioned earlier, the total lipid content of ND B. braunii cells was higher than in the control samples (Fig. 1b). After examining the lipidome, we noticed an augmented abundance ratio in most DAGs (Fig. 3c, d). The increased DAG accumulation may take place through several mechanisms reported in microalgae subjected to nutrient limitation: (i) acylation of de novo synthesized FAs (Li et al. 2012; Martin et al. 2014), (ii) or acylation of FAs recycled from membrane lipids which are liberated through the activity of acyl hydrolases (Sung Ho Cho and Thompson 1986; Li et al. 2012; Martin et al. 2014), into the glycerol backbone to produce glycerolipids such as DAG; or (iii) glycolipid- (Li et al. 2012) and GPL-derived DAG (Martin et al. 2014), that results from the removal of the polar head of these membrane lipids. The lipidome analysis also showed that around $93 \%$ and $87 \%$ of the TAGs identified were accumulated in D6 and D12 samples, respectively (Fig. 4d). TAG species with low degree of unsaturation (e.g., TAG-48:0/-48:2/50:0/-50:1/-52:1/-52:2/-54:2/-56:2/-58:1) are proposed to be the result of de novo synthesis pathways (Simionato et al. 2013; Li et al. 2014); nevertheless, they could also result from FA recycling (Simionato et al. 2013; Li et al. 2014). The increased abundance of highly unsaturated TAGs (e.g., TAG-50:4/-50:5/-50:6/-52:4/52:5/-52:6/-52:7/-52:8/-52:9) leads us to hypothesize that they may result from membranederived polyunsaturated FA, in agreement with the reduction in glycolipid abundance (Fig. 4b, c), which may be indicative of membrane derived-FA recycling into TAGs (Li et al. 2012, 2014; Kokabi et al. 2020).

With respect to membrane lipids, we identified several GPLs in B. braunii ND cells, namely PC, PG, and PS (Fig. 5a, b), detected mostly in D12 samples. The PG and PS abundance ratio was reduced, while the opposite was encountered for PC. These results share some similarities and differences with those published by other authors. For instance, Martin et al. (2014) reported a decrease in total GPLs (e.g., PE, PC, PS, PI) content of around 70\% and 33\% for Chlorella sp., and Nannochloropsis sp., respectively, with the exception of PG that experienced an increased in both microalgae. Li et al., (2014) conducted a study with Nannochloropsis sp., reporting the depletion of PC, PI, and PG, concurrent with the accumulation of TAG. White et al., (2019) in a study with Chlorella sp., recorded a reduction for several GPL classes (e.g., PE, PC, and PG). From our results, it is not possible to explain the preferential accumulation of PCs over the other GPLs identified, such as the non-nitrogen containing PG. In P-deprived microalgae cells, there are reports of PC and DGDG increase, which may suggest the re-assembly of DGDG from PC, hypothesizing that $\mathrm{PC}$ may transiently increase under $\mathrm{P}$ deprivation for its reuse in DGDG biosynthesis (Jouhet et al. 2003; Kokabi et al. 2020). In ND B. braunii cells at D12, we found increased abundance for $71 \%$ and $73 \%$ of the identified DGTSs (Fig. 4a) and DGDGs (Fig. 4b) respectively, as well as the global increase of neutral lipids (DAG, TAG; Figs. $3 d$ and $4 d$, respectively). However, the occurrence of a similar mechanism that may explain the concomitant PC, DGTS, DGDG, and neutral lipids accumulation that may point towards a possible redirection of PC-derived intermediates to structural and neutral lipids biosynthesis, requires further studies to be confirmed. In respect to the structural lipid DGTS, we found an increase taking place for a relevant number of species not only in PD at D6 but also in ND 
cells at D6 and D12 (Fig. 4a), contrary to reports of overall DGTS reduction in nutrient-limited microalgae cultures (Han et al. 2017; White et al. 2019). In addition, given the increased abundance of $\mathrm{PC}$ species found under $\mathrm{N}$ deprivation (Fig. 5b), we did not find a clear pattern of PC substitution with DGTS under the conditions evaluated in this study, as reported by other authors (Sato 1992; Harwood 2006).

A final aspect that worth highlighting is related to the preservation of membrane homeostasis. The increase of the DGDG/MGDG ratio is a common observation made in several studies of microalgae subjected to conditions were $\mathrm{N}$ deprivation/limitation is the stressor agent ( $\mathrm{Lu}$ et al. 2013; Abida et al. 2015); however, there is also evidence that other lipid remodeling responses can take place in microalgae coping with the same stressor. The studies performed with N-deprived Ettlia oleoabundans (Matich et al. 2018) and $C$. reinhardtii (Siaut et al. 2011), showed that a global reduction of chloroplast lipids (MGDG, DGDG, and SQDG), besides PG can occur concomitantly with TAGs accumulation. In the study performed with Chlorella sp., and Nannochloropsis sp. (Martin et al. 2014), a reduction of MGDGs and DGDGs was also reported, but SQDGs underwent a significant reduction in Chlorella sp., while in Nannochloropsis sp., the decrease was less drastic, and in both cases the PG content increased. Similar results with Nannochloropsis sp. were obtained by Li et al. (2014) in respect to MGDG, DGDG, and SQDG reduction, alongside the drop of PG content. Finally, in Chlamydomonas nivalis (Lu et al. 2013), the increased DGDG/ MGDG ratio was accompanied by a reduction of SQDG and a concomitant increase of PG. The above examples show that it is not possible to make a generalization regarding the remodeling responses of membrane lipids exhibited by microalgal cells under stress conditions. In our study with B. braunii, we observed a reduced abundance for MGDGs at the early and late stages of growth (Fig. 4c), with a concomitant increase in the abundance of over $60 \%$ of the identified DGDGs (Fig. 4b), which is in agreement with some of the studies aforementioned. However, the proper development of the chloroplasts and the functioning of the photosynthetic machinery requires an adequate balance among several lipid classes (Wada and Mizusawa 2009; Martin et al. 2014). Hence, the lipid remodeling responses under stress conditions not only involve galactolipids, but also other lipid classes, such as PG and sulfolipids, that despite not being comparatively as abundant as galactolipids, their importance should not be overlooked. From our data, it is not possible to infer all the mechanisms deployed by N-deprived B. braunii cells to maintain membrane homeostasis, especially in chloroplasts, given the observed PG and MGDG reduction. There is evidence that PG deficiency may be at least partially compensated by the anionic lipid SQDG, (Abida et al. 2015; White et al. 2019), which is not the case in ND $B$. braunii cells (Fig. 5 b), or by the not charged lipid DGDG
(Abida et al. 2015), that appears as the most likely possibility according to the abundance ratio calculations (Fig. 4b). The differences in the results of membrane lipid remodeling in this and other published studies may suggest a speciesspecific response to stress and may be indicative that in $B$. braunii the shunting of carbon flux from the membrane lipids to TAG biosynthesis occurred mainly by glycolipids (i.e., MGDG) and to a lesser extent by betaine lipids rather than GPLs degradation. Further research is necessary to unveil the mechanism of lipid membrane homeostasis in B. braunii under stress conditions.

In addition to the mentioned mechanisms for boosting glycerolipids accumulation, other existing macromolecules could also be degraded (i.e., CHOs and proteins) into lipid biosynthesis precursors ( $\mathrm{Li}$ et al. 2010, 2011). In our study, the significant reduction of in- and ex-CHOs in ND cells (Fig. 1d, e), especially at D12, might point towards a shift of carbon partitioning into neutral lipids as primary carbon and energy storage product, at the expense of CHOs.

\section{Effects of phosphate deprivation in B. braunii lipidome}

$\mathrm{P}$ is a critical nutrient in all domains of life (Dyhrman 2016). The effects of $P$ deprivation have been widely studied in microalgae and cyanobacteria (Martin et al. 2011; Cañavate et al. 2017; Matich et al. 2018; Kokabi et al. 2020). The effect of $\mathrm{P}$ deprivation in boosting cellular lipid accumulation has rendered contradictory results in microalgae. There are reports of minor changes (Cañavate et al. 2017; Matich et al. 2018) or even reduction (Cañavate et al. 2017), while there are other cases where an increased lipid content is observed (Kamalanathan et al. 2015; Cañavate et al. 2017). In our study, we found that $\mathrm{P}$ deprivation triggers $B$. braunii lipid accumulation only at early stages of growth, since a longer exposure to this stress condition has the opposite effect, causing a significant reduction of the total lipid content (Fig. 1b). Several remodeling events took place in the lipidome of PD B. braunii cells compared to the control samples. The abundance/reduction ratios of DAG (Fig. 3c, d), DGTS (Fig. 4a), and DGDG (Fig. 4b) species were not just influenced by the absence of $\mathrm{P}$ in the medium, but also by the time of exposure to this stress, since the abundance pattern changed drastically in the two time points evaluated. On the contrary, the response was more consistent for the structural glycolipid, MGDG (Fig. 4c), since we noticed a global reduction of MGDG at early (D6) and late (D12) stages of culture.

TAG accumulation under $\mathrm{P}$ stress has been reported in a number of studies (Rodolfi et al. 2009; Abida et al. 2015). In $B$. braunii cells, TAGs were predominantly built up at the early stage of growth (Fig. 4d) as reported for other microalgae upon short-term exposure to $\mathrm{P}$ deprivation (Mühlroth 
et al., 2017). However, after prolonged PD stress, TAG accumulation seemed to slow down, with a significant number of TAGs being degraded. Considering the abundance ratio trend, we determined that at D6, the higher abundance of DAGs and TAGs, and to some extent several polar lipids (i.e., DGDG and DGTS), were responsible for the increase in total lipid content. At D12, the reduction of a number of GPLs, galactolipids, DGTS, and TAGs, may account for the reduced total lipid content.

Meanwhile, our results of GPLs and SQDG reduction upon exposure of cells to prolonged $\mathrm{P}$ deprivation (Fig. 5a, b), differed to some extent from the work published by other authors. In cyanobacteria and eukaryotic algae, it is reported that the P-rich PG can be substituted by other non-P-containing lipids (i.e., SQDG, DGDG), while the extraplastidial PC can be replaced by taxonomically specific betaine lipids (Abida et al. 2015; Mühlroth et al. 2017). In our case, we noticed increase in DGTS at the early stage of growth (D6) (Fig. 4a); while at later stages, both SQDG (Fig. 5b) and DGTS species were reduced. These findings are also partially opposed to schemes of GPLs recycling proposed for other microalgae, where GPLs are broken down to glycerol3-phophate, FAs, and DAG, and the products are used to synthesize mainly DGTS and SQDG in exponential growth and, later, for the synthesis of TAGs and galactolipids in stationary growth (Mühlroth et al. 2017). In our study, we could hypothesize that in B. braunii cells, GPLs degradation products may be preferentially directed to TAG biosynthesis, but only at late stages of growth (Fig. 5b), since GPLs degradation was negligible at D6 (Fig. 5a). This might coincide with the need to mobilize GPL-bounded P, possibly acting as secondary $\mathrm{P}$ storage upon cell exposure to prolonged $\mathrm{P}$ deprivation. On the other hand, the overall trend of MGDG degradation found in B. braunii samples (Fig. 4c) leads us to suggest that this galactolipid class may be recycled into neutral lipids (i.e., DAG and TAG) at D6 (Figs. 3c and 4d) and D12 (Fig. 4d), and may act as a precursor for other structural lipids (i.e., DGTS, DGDG) at early stages of growth (Fig. 4a, b).

The above findings indicate that at early stages of growth, B. braunii probably had availability of intracellular $\mathrm{P}$ that might have been stored before the cells were transferred to the P-deprived medium (Casadevall et al. 1985), and was sufficient to sustain cellular metabolism and growth at a similar rate to B. braunii cells under P-replete conditions (Fig. 1a). However, upon exposure to prolonged $\mathrm{P}$-deprivation, the $\mathrm{P}$ levels may become critically low with a subsequent arrest of growth and a reduced lipid content. It is well documented that algae are capable of absorbing $\mathrm{P}$ in amounts largely exceeding cell requirements, and such $\mathrm{P}$ surplus is stored as pholyphosphate granules (Dyhrman 2016), that constitute a reservoir to sustain cell growth in a P-free medium. These results indicate that $B$. braunii may be capable of storing
P surplus, which nevertheless was not sufficient to sustain growth and lipid production under conditions of prolonged $\mathrm{P}$ deprivation.

The GPLs decrease following P depletion found across microalgae and observed in the present study is compatible with a role for GPLs as P storage compounds (Dyhrman 2016; Cañavate et al. 2017), and constitutes one of several mechanisms exhibited by microalgae for maintaining $\mathrm{P}$ homeostasis. However, the magnitude of this role seems to be highly variable as it depends on the total microalgal GPL content, which is susceptible to turnover under the influence of $P$ availability (Cañavate et al. 2017). In species with an intrinsically low GPL content, it is very unlikely that GPLs are involved in P stock regulation, as may be the case of $B$. braunii, giving the low number of GPLs detected compared to other structural lipids. This finding provides evidence that a true physiological exchange between betaine lipids and GPL cannot always be assumed (Cañavate et al. 2017). It is suggested that betaine lipids might play a more diversified role than GPL in microalgal lipid metabolism and that betaine lipids replacing GPLs in P-scarce environments cannot be regarded as a common phenomenon (Cañavate et al. 2017).

\section{Lipidome remodeling of $\mathbf{B}$. braunii cells grown under high carbon dosage}

B. braunii cells cultivated under different $\mathrm{NaHCO}_{3}$ regimes displayed a group of lipids whose abundance was increased or decreased concomitantly with the $\mathrm{NaHCO}_{3}$ concentration (Figs. 3c, $d$ and 4a-d). The accumulation of structural lipids (i.e., DGTS, DGDG, MGDG) was particularly enhanced at early stages of growth (Fig. 4a-c), particularly for 1 and $2 \%$ $\mathrm{NaHCO}_{3}$ samples, in contrast to the condition-dependent reductions observed under nutrient (i.e., $\mathrm{N}$ and $\mathrm{P}$ ) deprivation. In studies performed with $\mathrm{N}$-deprived $C$. reinhardtii, it was suggested that DGTS remodeling occurs in a temporal manner in response to overall cell density and environmental conditions (Yang et al. 2015). We observed an increased abundance of the structural lipids in particular for 1 and $2 \%$ $\mathrm{NaHCO}_{3}$ cells, which corresponded to the conditions where the highest biomass productivities were reached (Fig. 1a). Thus, it is expected that cells with the highest division rates require larger amounts of structural lipids, whose synthesis was enhanced, especially at the earliest time point. It was also remarkable to note the differential profile of nutrient consumption from the medium, where we observed that in cells grown on medium with $0.1 \% \mathrm{NaHCO}_{3}$, the depletion of $\mathrm{P}$ from the medium occurred faster (Fig. 1h), which may trigger a similar response to P-deprived cells, as we also noticed a similar pattern of DGDG and MGDG degradation at D6 and D12 (Fig. 4b, c), as well as DGTS reduction at D12 (Fig. 4a). 
The total lipid content was increased compared to the control samples, and despite it was slightly lower than the $\mathrm{N}$-deprived treatment, we did not observe a substantial reduction of TAGs at the later stage of growth (Fig. 4d). It is interesting to note that when high carbon dosages are supplied to $B$. braunii in the form of $\mathrm{NaHCO}_{3}$, the neutral lipids fraction (i.e., DAG, and TAG) is enriched compared to the control samples; and unlike the N-starved cells, accumulation of TAGs occurred at later stages of growth with minimal degradation (Fig. 4d). DAG species were preferentially accumulated at the early stage of growth (D6) (Fig. 3c), since samples taken at D12 showed a reduction of the abundance ratios for a substantial number of DAGs (Fig. 3d). Whether this may be the result of a reduced rate of DAGs synthesis or a higher flux towards the reactions of fatty acyl assembly to produce glycerolipids, or both, requires further research to be determined. Another question that remains open is the origin of the precursors for TAG formation at later stages of growth, since DAG accumulation seems to slow-down compared to the control samples, while a concomitant reduction was also appreciated for the structural lipids, DGTS, and galactolipids, which may point to a mechanism of lipid recycling into TAGs. However, further research is necessary to elucidate the contribution of the de novo synthesis and lipid remodeling routes to neutral lipid accumulation in $B$. braunii cells cultivated under a high carbon dosage regime. The effect of a larger TAG accumulation was more evident in the medium with $1 \%$ and $2 \% \mathrm{NaHCO}_{3}$, which underline the importance of keeping a proper $\mathrm{C} / \mathrm{N}$ ratio to sustain high biomass and lipid yield.

After taking a close look at the TAGs that were accumulated at the early (D6) and late stages of growth (D12), we did not identify a pattern that might be indicative of the preferential accumulation of a specific group of TAGs, since over $70 \%$ of the accumulated species were common to all samples. On the other hand, after comparing the TAGs distributions of samples taken at the same sampling points, of cells grown on $\mathrm{NaHCO}_{3}$ and the $\mathrm{N}$-deprived cultures, we identified a group of TAGs whose abundance ratios were increased exclusively at the early and the late stage of growth, which corresponded mostly to polyunsaturated species (Fig. 4d). The question remains as to what can be attributed this common feature, since the extracellular medium of cells cultivated with $\mathrm{NaHCO}_{3}$ still contained considerable amounts of nutrients (i.e., $\mathrm{P}$ and $\mathrm{N}$ ), especially in 1 and $2 \% \mathrm{NaHCO}_{3}$ samples (Fig. $1 \mathrm{~g}$, h). Thus, a nutrient deficiency response at least for these two elements does not seem to be a likely explanation. On the other hand, the increase of these TAGs occurred on samples taken at specific days, and therefore the possibility remains that the change in the profile of these TAGs may be related to the stage of growth of the culture and to some extent may also be associated with lipid remodeling events, given the condition-specific reductions observed for some polyunsaturated species of chloroplast lipids, as well as GPLs, betaine lipids, and DAGs. Further research will be required to have an in-depth understanding of the physiological mechanisms behind these changes.

The use of $\mathrm{NaHCO}_{3}$ has been evaluated in different algae, with interesting results in terms of larger biomass and/or lipid accumulation (Pimolrat et al. 2010; Gardner et al. 2013). In B. braunii, there are but a few reports about the use of $\mathrm{NaHCO}_{3}$ as carbon source and its effect on growth and total lipid content (Tanoi et al. 2011; Wei-Bao Kong 2012; Salbitani et al. 2019), and a detailed analysis about the lipid composition and the impact of this carbon source on other determinants of growth and productivity was lacking.

\section{Conclusions}

Botryococcus braunii displayed differential responses upon diverse nutrient scenarios, especially when it comes to carbon distribution and overall productivity. Our results revealed that under high inorganic carbon dosages, the biomass and lipid productivity can be substantially boosted due to the enhanced photosynthetic rates. Accordingly, there might be place for further productivity improvements via optimization of light configuration by on-demand irradiance tuning. Moreover, the lipidomic analysis showed that the plasticity of lipid metabolism upon diverse nutritional contexts makes nutrient tinkering another way to induce desirable biochemical traits (i.e., enrichment of neutral lipid fraction), to improve biomass suitability for further bioenergy valorization.

Supplementary Information The online version contains supplementary material available at https://doi.org/10.1007/s10811-021-02544-7.

Acknowledgements The authors thank Änne Michaelis, Aleksandra Skirycz, and Yariv Brotman (Max Planck Institute of Molecular Plant Physiology_Potsdam, Germany) for their support with the lipid analysis.

Author contribution Néstor Giraldo: Conceptualization, Methodology, Investigation, Formal analysis, Writing - original draft preparation. Sandra Correa: Data Curation, Formal analysis, Writing - original draft preparation, Writing- Reviewing and Editing. Andrés Arbeláez: Methodology, Investigation, Writing- Reviewing and Editing. Felix L. Figueroa: Supervising, Writing- Reviewing and Editing Rigoberto Ríos-Estepa: Conceptualization, Supervision, Writing- Reviewing and Editing Lucía Atehortúa: Supervision, Project administration, Funding acquisition, Writing- Reviewing and Editing.

Funding Open Access funding enabled and organized by Projekt DEAL. This work was supported by the Agencia Nacional de Hidrocarburos (ANH), Ministerio de Ciencia, Tecnología e Innovación Colciencias and Universidad de Antioquia under the grant 721-2015 "Convocatoria para la formación de recurso humano en Colombia en el área de hidrocarburos, a través de proyectos de investigación año 2015". 
Data availability The datasets used and/or analyzed during the current study are available from the corresponding author on reasonable request.

\section{Declarations}

Competing interests The authors declare no competing interests.

Open Access This article is licensed under a Creative Commons Attribution 4.0 International License, which permits use, sharing, adaptation, distribution and reproduction in any medium or format, as long as you give appropriate credit to the original author(s) and the source, provide a link to the Creative Commons licence, and indicate if changes were made. The images or other third party material in this article are included in the article's Creative Commons licence, unless indicated otherwise in a credit line to the material. If material is not included in the article's Creative Commons licence and your intended use is not permitted by statutory regulation or exceeds the permitted use, you will need to obtain permission directly from the copyright holder. To view a copy of this licence, visit http://creativecommons.org/licenses/by/4.0/.

\section{References}

Abida H, Dolch L-J, Meï C, Villanova V, Conte M, Block MA, Finazzi G, Bastien O, Tirichine L, Bowler C, Rébeillé F, Petroutsos D, Jouhet J, Maréchal E (2015) Membrane glycerolipid remodeling triggered by nitrogen and phosphorus starvation in Phaeodactylum tricornutum. Plant Physiol 167:118-136

Arun J, Gopinath KP, SundarRajan PS, Felix V, Monica MJ, Mamolan $\mathrm{R}$ (2020) A conceptual review on microalgae biorefinery through thermochemical and biological pathways: bio-circular approach on carbon capture and wastewater treatment. Bioresour Technol Rep 11:100477

Baker NR (2008) Chlorophyll fluorescence: a probe of photosynthesis in vivo. Annu Rev Plant Biol 59:89-113

Banerjee A, Sharma R, Chisti Y, Banerjee UC (2002) Botryococcus braunii: a renewable source of hydrocarbons and other chemicals. Crit Rev Biotechnol 22:245-279

Barajas-Solano A, Guzman-Monsalve A, Kafarov V (2016) Effect of carbon-nitrogen ratio for the biomass production, hydrocarbons and lipids on Botryoccus braunii UIS 003. Chem Eng Trans 49:247-252

Bell SA, Niehaus TD, Nybo SE, Chappell J (2014) Structure-function mapping of key determinants for hydrocarbon biosynthesis by squalene and squalene synthase-like enzymes from the green alga Botryococcus braunii race B. Biochemistry 53:7570-7581

Biller P, Sharma BK, Kunwar B, Ross AB (2015) Hydroprocessing of bio-crude from continuous hydrothermal liquefaction of microalgae. Fuel 159:197-205

Blifernez-Klassen O, Chaudhari S, Klassen V, Wördenweber R, Steffens T, Cholewa D, Niehaus K, Kalinowski J, Kruse O (2018) Metabolic survey of Botryococcus braunii: impact of the physiological state on product formation. PLoS One 13:e0198976

Bolton JJ (2006) Algal culturing techniques. J Exp Mar Biol Ecol $336: 262$

Breuer G, Lamers PP, Martens DE, Draaisma RB, Wijffels RH (2012) The impact of nitrogen starvation on the dynamics of triacylglycerol accumulation in nine microalgae strains. Bioresour Technol 124:217-226

Cañavate JP, Armada I, Hachero-Cruzado I (2017) Interspecific variability in phosphorus-induced lipid remodelling among marine eukaryotic phytoplankton. New Phytol 213:700-713
Casadevall E, Dif D, Largeau C, Gudin C, Chaumont D, Desanti O (1985) Studies on batch and continuous cultures of Botryococcus braunii: hydrocarbon production in relation to physiological state, cell ultrastructure, and phosphate nutrition. Biotechnol Bioeng 27:286-295

Cheng P, Ji B, Gao L, Zhang W, Wang J, Liu T (2013) The growth, lipid and hydrocarbon production of Botryococcus braunii with attached cultivation. Bioresour Technol 138:95-100

Cheng P, Okada S, Zhou C, Chen P, Huo S, Li K, Addy M, Yan X, Ruan RR (2019) High-value chemicals from Botryococcus braunii and their current applications-a review. Bioresour Techno. 291:121911

Choi GG, Kim BH, Ahn CY, Oh HM (2011) Effect of nitrogen limitation on oleic acid biosynthesis in Botryococcus braunii. J Appl Phycol 23:1031-1037

Chong J, Wishart DS, Xia J (2019) Using MetaboAnalyst 4.0 for comprehensive and integrative metabolomics data analysis. Curr Protoc Bioinformatics 68:e86

Cleland J (2013) World population growth; past, present and future. Environ Resour Econ 55:543-554

Cui Y, Zhang H, Lin S (2017) Enhancement of non-photochemical quenching as an adaptive strategy under phosphorus deprivation in the dinoflagellate Karlodinium veneficum. Front Microbiol $8: 404$

Dayananda C, Sarada R, Usha Rani M, Shamala TR, Ravishankar GA (2007) Autotrophic cultivation of Botryococcus braunii for the production of hydrocarbons and exopolysaccharides in various media. Biomass and Bioenergy 31:87-93

Du H, Ren J, Li Z, Zhang H, Wang K, Lin B, Zheng S, Zhao C, Meng C, Gao Z (2020) Plant growth regulators affect biomass, protein, carotenoid, and lipid production in Botryococcus braunii. Aquac Int 28:1319-1340

Dyhrman ST (2016) Nutrients and their acquisition: Phosphorus physiology in microalgae. In: Borowitzka MA, Beardall L, Raven JA (eds) The Physiology of Microalgae. Springer, Cham, pp $155-183$

Ermavitalini D, Yuliansari N, Prasetyo EN, Saputro TB (2017) Efect of Gamma ${ }^{60} \mathrm{Co}$ irradiation on the growth, lipid content and fatty acid composition of Botryococcus sp. microalgae. Biosaintifika 9:58-65

Eroglu E, Okada S, Melis A (2011) Hydrocarbon productivities in different Botryococcus strains: Comparative methods in product quantification. J Appl Phycol 23:763-775

Fang L, Sun D, Xu Z, He J, Qi S, Chen X, Chew W, Liu J (2015) Transcriptomic analysis of a moderately growing subisolate Botryococcus braunii 779 (Chlorophyta) in response to nitrogen deprivation. Biotechnol Biofuels 8:130

Figueroa FL, Bonomi-Barufi J, Celis-Plá PSM, Nitschke U, Arenas F, Connan S, Abreu MH, Malta EJ, Conde-Álvarez R, Chow F, Mata MT, Meyerhoff O, Robledo D, Stengel DB (2021) Shortterm effects of increased $\mathrm{CO}_{2}$, nitrate and temperature on photosynthetic activity in Ulva rigida (Chlorophyta) estimated by different pulse amplitude modulated fluorometers and oxygen evolution. J Exp Bot 72:491-509

Gardner R, Lohman E, Cooksey K, Gerlach KE, Pryton BM (2013) Cellular cycling, carbon utilization, and photosynthetic oxygen production during bicarbonate-induced triacylglycerol accumulation in a Scenedesmus sp. Energies 6:6060-6076

Giordano M, Beardall J, Raven JA (2005) $\mathrm{CO}_{2}$ concentrating mechanisms in algae: mechanisms, environmental modulation, and evolution. Annu Rev Plant Biol 56:99-131

Giraldo Calderón ND, Díaz Bayona KC, Atehortúa Garcés L (2018) Immobilization of the green microalga Botryococcus braunii in polyester wadding: effect on biomass, fatty acids, and exopolysaccharide production. Biocatal Agric Biotechnol 14:80-87 
Giraldo ND, Buchelly RJR, Hincapié DE, Atehortua L (2020) Transformation of brewery subproducts into valuable biomass using mixotrophic culture of Chlorella pyrenoidosa and associated bacteria. Braz Arch Biol Technol 63:2020190229

Giraldo ND, Correa SM, Arbeláez A, Figueroa FL, Rios-Estapa R, Atehortúa L (2021) Reducing self-shading effects in Botryococcus braunii cultures: effect of $\mathrm{Mg}^{2+}$ deficiency on optical and biochemical properties, photosynthesis and lipidomic profile. Bioresour Bioprocess 8:33

Gouveia JD, Ruiz J, van den Broek LAM, Hesselink T, Peters S, Kleinegris DMM, Smith AG, van der Veen D, Barbosa MJ, Wijffels RH (2017) Botryococcus braunii strains compared for biomass productivity, hydrocarbon and carbohydrate content. $\mathrm{J}$ Biotechnol 248:77-86

Griffiths MJ, Garcin C, van Hille RP, Harrison STL (2011) Interference by pigment in the estimation of microalgal biomass concentration by optical density. J Microbiol Methods 85:119-123

Grund M, Jakob T, Wilhelm C, Bühler B, Schmid A (2019) Electron balancing under different sink conditions reveals positive effects on photon efficiency and metabolic activity of Synechocystis sp. PCC 6803. Biotechnol Biofuels 12:43

Guleria P, Kumar V (2020) GMO to eradicate malnutrition: Current status. Curr Nutr Food Sci 17:4-10

Han D, Jia J, Li J, Sommerfend M, Xu J, Hu Q (2017) Metabolic remodeling of membrane glycerolipids in the microalga Nannochloropsis oceanica under nitrogen deprivation. Front Mar Sci 4:242

Harwood JL (2006) Membrane lipids in algae. In: Siegenthaler P-A, Murata N (eds) Lipids in photosynthesis: structure, function and genetics. Kluwer, Dordrecht, pp 53-64

Head IM, Gray ND (2016) Microbial biotechnology 2020; microbiology of fossil fuel resources. Microb Biotechnol 9:626-634

Hejazi MA, Wijffels RH (2004) Milking of microalgae. Trends Biotechnol 22:189-194

Hockin NL, Mock T, Mulholland F, Kopriva S, Malin G (2012) The response of diatom central carbon metabolism to nitrogen starvation is different from that of green algae and higher plants. Plant Physiol 158:299-312

Hogewoning SW, Wientjes E, Douwstra P, Trouwborst G, van Ieperen W, Croce R, Harbinson J (2012) Photosynthetic quantum yield dynamics: from photosystems to leaves. Plant Cell 24:1921-1935

Jerez CG, Malapascua JR, Sergejevová M, Figueroa FL, Masojidek J (2016) Effect of nutrient starvation under high irradiance on lipid and starch accumulation in Chlorella fusca (Chlorophyta). Mar Biotechnol 18:24-36

Jin J, Dupré C, Yoneda K, Watanabe MM, Legrand J, Grizeau D (2016) Characteristics of extracellular hydrocarbon-rich microalga Botryococcus braunii for biofuels production: Recent advances and opportunities. Process Biochem 51:1866-1875

Jouhet J, Maréchal E, Bligny R, Joyard J, Block MA (2003) Transient increase of phosphatidylcholine in plant cells in response to phosphate deprivation. FEBS Letters 544:63-68

Kalacheva GS, Zhila NO, Volova TG, Gladyshev MI (2002) The effect of temperature on the lipid composition of the green alga Botryococcus. Microbiology 71:286-293

Kamalanathan M, Gleadow R, Beardall J (2015) Impacts of phosphorus availability on lipid production by Chlamydomonas reinhardtii. Algal Res 12:191-196

Kamalanathan M, Pierangelini M, Shearman LA, Greadow R, Beardall J (2016) Impacts of nitrogen and phosphorus starvation on the physiology of Chlamydomonas reinhardtii. J Appl Phycol 28:1509-1520

Kilbane JJ (2016) Future applications of biotechnology to the energy industry. Front Microbiol 7:86
Kim GY, Heo J, Kim HS, Han JI (2017) Bicarbonate-based cultivation of Dunaliella salina for enhancing carbon utilization efficiency. Bioresour Technol 237:72-77

Kleinert C, Griehl C (2020) Identification of suitable Botryococcus braunii strains for non-destructive in situ hydrocarbon extraction. J Appl Phycol 33:785-798

Kobayashi K (2016) Role of membrane glycerolipids in photosynthesis, thylakoid biogenesis and chloroplast development. J Plant Res 129:565-580

Kokabi K, Gorelova O, Zorin B, Didi-Cohen S, Itkin M, Malitsky S, Solovchenko A, Boussiba S, Khozin-Goldberg I (2020) Lipidome remodeling and autophagic respose in the arachidonic-acid-rich microalga Lobosphaera incisa under nitrogen and phosphorous deprivation. Front Plant Sci 11:614846

Kong W-B (2012) Enhancement of biomass and hydrocarbon productivities of Botryococcus braunii by mixotrophic cultivation and its application in brewery wastewater treatment. Afr J Microbiol Res 6:1489-1496

Kumari P, Kumar M, Reddy CRK, Jha B (2014) Nitrate and phosphate regimes induced lipidomic and biochemical changes in the intertidal macroalga Ulva lactuca (Ulvophyceae, Chlorophyta). Plant Cell Physiol 55:52-63

Li J, Han D, Wang D, Ning K, Jia J, Wei L, Jing X, Huang S, Chen J, Li Y, Hu Q, Xu J (2014) Choreography of transcriptomes and lipidomes of Nannochloropsis reveals the mechanisms of oil synthesis in microalgae. Plant Cell 26:1645-1665

Li M, Shi X, Guo C, Lin S (2016) Phosphorus deficiency inhibits cell division but not growth in the dinoflagellate Amphidinium carterae. Front Microbiol 7:826

Li X, Moellering ER, Liu B, Johhny C, Fedewa M, Sears BB, Kuo M-H, Benning C (2012) A galactoglycerolipid lipase is required for triacylglycerol accumulation and survival following nitrogen deprivation in Chlamydomonas reinhardtii. Plant Cell 24:4670-4686

Li Y, Han D, Hu G, Sommerfeld M, Hu Q (2010) Inhibition of starch synthesis results in overproduction of lipids in Chlamydomonas reinhardtii. Biotechnol Bioeng 107:258-268

Li Y, Han D, Sommerfeld M, Hu Q (2011) Photosynthetic carbon partitioning and lipid production in the oleaginous microalga Pseudochlorococcum sp. (Chlorophyceae) under nitrogen-limited conditions. Bioresour Technol 102:123-129

Lu N, Wei D, Chen F, Yang ST (2013) Lipidomic profiling reveals lipid regulation in the snow alga Chlamydomonas nivalis in response to nitrate or phosphate deprivation. Process Biochem 48:605-613

Lupi FM, Fernandes HML, Tomé MM, Sá-Correia I, Novais JM (1994) Influence of nitrogen source and photoperiod on exopolysaccharide synthesis by the microalga Botryococcus braunii UC 58. Enzyme Microb Technol 16:546-550

Malapascua JRF, Jerez CG, Sergejevová M, Figueroa FL, Masojidek J (2014) Photosynthesis monitoring to optimize growth of microalgal mass cultures: application of chlorophyll fluorescence techniques. Aquat Biol 22:123-140

Bromke MA, Hochmuth A, Takayuki T, Fernie AR, Giavalisco P, Burgos A, Willmitzer L, Brotman Y (2015) Liquid chromatography high-resolution mass spectrometry for fatty acid profiling. The Plant Journal 81:529-536

Martin GJ, Hill DR, Olmstead IL, Bergamin A, Shears MJ, Dias DA, Kentish SE, Scales PJ, Botté CY, Callahan DL (2014) Lipid profile remodeling in response to nitrogen deprivation in the microalgae Chlorella sp. (Trebouxiophyceae) and Nannochloropsis sp. (Eustigmatophyceae). PLoS ONE 9:e103389

Martin P, Van Mooy BAS, Heithoff A, Dyhrman ST (2011) Phosphorus supply drives rapid turnover of membrane phospholipids in the diatom Thalassiosira pseudonana. ISME J 5:1057-1060 
Masuko T, Minami A, Iwasaki N, Majima T, Nishimura S, Lee YC (2005) Carbohydrate analysis by a phenol-sulfuric acid method in microplate format. Anal Biochem 339:69-72

Matich EK, Ghafari M, Camgoz E, Caliskan E, Pfeifer BA, Haznedaroglu BZ, Atilla-Gokcumen GE (2018) Time-series lipidomic analysis of the oleaginous green microalga species Ettlia oleoabundans under nutrient stress. Biotechnol Biofuels 11:29

Maxwell DP, Falk S, Huner NP (1995) Photosystem II excitation pressure and development of resistance to photoinhibition. I. Lightharvesting complex II abundance and zeaxanthin content in Chlorella vulgaris. Plant Physiol 107:687-694

Metzger P, Berkaloff C, Casadevall E, Coute A (1985) Alkadiene- and botryococcene-producing races of wild strains of Botryococcus braunii. Phytochemistry 24:2305-2312

Metzger P, David M, Casadevall E (1986) Biosynthesis of triterpenoid hydrocarbons in the B-race of the green alga Botryococcus braunii. Sites of production and nature of the methylating agent. Phytochemistry 26:129-134

Metzger P, Largeau C (1999) Chemicals of Botryococcus braunii. In: Cohen Z (ed) Chemicals from microalgae. Taylor \& Francis, London, pp 205-260

Metzger P, Largeau C (2005) Botryococcus braunii: a rich source for hydrocarbons and related ether lipids. Appl Microbiol Biotechnol 66:486-496

Metzger P, Pouet Y, Summons R (1997) Chemotaxonomic evidence for the similarity between Botryococcus braunii $\mathrm{L}$ race and Botryococcus neglectus. Phytochemistry 44:1071-1075

Mirjafari P, Asghari K, Mahinpey N (2007) Investigating the application of enzyme carbonic anhydrase for $\mathrm{CO}_{2}$ sequestration purposes. Ind Eng Chem Res 46:921-926

Molnár I, Lopez D, Wisecaver JH, Devarenne TP, Weiss TL, Pellegrini M, Hackett JD (2012) Bio-crude transcriptomics: gene discovery and metabolic network reconstruction for the biosynthesis of the terpenome of the hydrocarbon oil-producing green alga, Botryococcus braunii race B (Showa). BMC Genomics 13:576

Mühlroth A, Winge P, El Assimi A, Jouhet J, Maréchal E, HohmannMarriott MF, Vadstein O, Bones AM (2017) Mechanisms of phosphorus acquisition and lipid class remodeling under $\mathrm{P}$ limitation in a marine microalga. Plant Physiol 175:1543-1559

Murprayana R, Pukan MSH, Soedarmodjo TP, et al (2021) The effects of UV-C and $\mathrm{HNO}_{2}$ mutagen, $\mathrm{pH}$ and the use of commercial fertilizers on the growth of microalgae Botryococcus braunii. IOP Conf Ser Mater Sci Eng 1053:12095

Muzika WA, Khan NE, Jackson LM, Winograd N, Curtis WR (2015) Production of biofuel-related isoprenoids derived from Botryococcus braunii algae. In: McGenity T., Timmis K., Nogales B. (eds) Hydrocarbon and Lipid Microbiology Protocols. Springer Protocols Handbooks. Springer, Berlin pp 141-152

Navarro Gallón SM, Alpaslan E, Wang M, Larese-Casanova P, Londoño ME, Atehortúa L, Pavón JJ, Webster TJ (2019) Characterization and study of the antibacterial mechanisms of silver nanoparticles prepared with microalgal exopolysaccharides. Mat Sci Eng C 99:685-695

Neidhardt J, Benemann JR, Zhang L, Melis A (1998) Photosystem-II repair and chloroplast recovery from irradiance stress: relationship between chronic photoinhibition, light-harvesting chlorophyll antenna size and photosynthetic productivity in Dunaliella salina (green algae). Photosynth Res 56:175-184

Niehaus TD, Kinison S, Okada S, Yeo YS, Bell SA, Cui P, Devarenne TP, Chappell J (2012) Functional identification of triterpene methyltransferases from Botryococcus braunii race B. J Biol Chem 287(11):8163-73

Niehaus TD, Okada S, Devarenne TP, Watt DS, Sviripa V, Chappell J (2011) Identification of unique mechanisms for triterpene biosynthesis in Botryococcus braunii. Proc Natl Acad Sci U S A 108:12260-12265

Okada S, Murakami M, Yamaguchi K (1995) Hydrocarbon composition of newly isolated strains of the green microalga Botryococcus braunii. J Appl Phycol 7:555-559

Okada S, Murakami M, Yamaguchi K (1997) Hydrocarbon production by the yayoi, a new strain of the green microalga Botryococcus braunii. Appl Biochem Biotechnol 67:79-86

Pancha I, Chokshi K, George B, Ghosh T, Paliwal C, Maurya R, Mishra S (2014) Nitrogen stress triggered biochemical and morphological changes in the microalgae Scenedesmus sp. CCNM 1077. Bioresour Technol 156:146-154

Pessarakli M (2016) Handbook of Photosynthesis, 3rd edn. CRC Press, Boca Raton

Pimolrat P, Direkbusarakom S, Chinajariyawong C, Powtongsook S (2010) The effect of sodium bicarbonate concentrations on growth and biochemical composition of Chaetoceros gracilis Schutt. J Fish Environ 34:40-47

Powell N, Shilton A, Chisti Y, Pratt S (2009) Towards a luxury uptake process via microalgae-defining the polyphosphate dynamics. Water Res 43:4207-4213

Ranga Rao A, Sarada R, Ravishankar GA (2007) Influence of $\mathrm{CO}_{2}$ on growth and hydrocarbon production in Botryococcus braunii. J Microbiol Biotechnol 17:414-419

Rodolfi L, Chini Zittelli G, Bassi N, Padovani G, Biondi N, Bonini G, Tredici MR (2009) Microalgae for oil: Strain selection, induction of lipid synthesis and outdoor mass cultivation in a low-cost photobioreactor. Biotechnol Bioeng 102:100-112

Sakamoto K, Baba M, Suzuki I, Watanabe MM, Shiraiwa Y (2012) Optimization of light for growth, photosynthesis, and hydrocarbon production by the colonial microalga Botryococcus braunii BOT-22. Bioresour Technol 110:474-479

Salbitani G, Barone CMA, Carfagna S (2019) Effect of bicarbonate on growth of the oleaginous microalga Botryococcus braunii. Int J Plant Biol 10:35-37

Sato N (1992) Betaine Lipids. Bot Mag Tokyo 105:185-197

Şengül AB, Rahman MM, Asmatulu E (2019) Evaluation of media and light source effects on the growth of Botryococcus braunii for biofuel production. Int J Environ Sci Technol. https://doi.org/10. 1007/s13762-018-1966-6

Siaut M, Cuiné S, Cagnon C, Fessler B, Nguyen M, Carrier P, Beyly A, Beisson F, Triantaphylides C, Li-Beisson Y, Peltier G(2011) Oil accumulation in the model green alga Chlamydomonas reinhardtii: characterization, variability between common laboratory strains and relationship with starch reserves. BMC Biotechnology $11: 7$

Simionato D, Block MA, La Rocca N, Jouhet J, Maréchal E, Finazzi G, Morosinotto T (2013) The response of Nannochloropsis gaditana to nitrogen starvation includes de novo biosynthesis of triacylglycerols, a decrease of chloroplast galactolipids, and reorganization of the photosynthetic apparatus. Eukaryot Cell 12:665-676

Singhal A, Prashant (2020) Biofuels: perspective for sustainable development and climate change mitigation. In: Kumar N (ed) Biotechnology for biofuels: a sustainable green energy solution. Springer, Singapore, pp 1-22

Srinivasan R, Mageswari A, Subramanian P, Suganthi C, Chaitanyakumar A, Aswini V, Gothandam KM (2018) Bicarbonate supplementation enhances growth and biochemical composition of Dunaliella salina V-101 by reducing oxidative stress induced during macronutrient deficit conditions. Sci Rep 8:6972

Cho SH, Thompson GA (1986) Properties of a fatty acyl hydrolase preferentially attacking monogalactosyldiacylglycerols in Dunaliella salina chloroplasts. Biochim Biophys Acta - Lipids Lipid Metab 878:353-359 
Tanoi T, Kawachi M, Watanabe M (2011) Effects of carbon source on growth and morphology of Botryococcus braunii. J Appl Phycol 23:25-33

Tcherkez GGB, Farquhar GD, Andrews TJ (2006) Despite slow catalysis and confused substrate specificity, all ribulose bisphosphate carboxylases may be nearly perfectly optimized. Proc Natl Acad Sci U S A 103:7246-7251

Thapa HR, Naik MT, Okada S, Takada K, Molnar I, Xu Y, Devarenne TP (2016) A squalene synthase-like enzyme initiates production of tetraterpenoid hydrocarbons in Botryococcus braunii Race L. Nat Commun 7:11198

Tu Z, Liu L, Lin W, Xie Z, Luo J (2018) Potential of using sodium bicarbonate as external carbon source to cultivate microalga in non-sterile condition. Bioresour Technol 266:109-115

Umetani I, Janka E, Sposób M, Hulatt CJ, Kleiven S, Bakke R (2021) Bicarbonate for microalgae cultivation: a case study in a chlorophyte, Tetradesmus wisconsinensis isolated from a Norwegian lake. J Appl Phycol 33:1341-1352

Vadlamani A, Pendyala B, Viamajala S, Varanasi S (2019) High productivity cultivation of microalgae without concentrated $\mathrm{CO}_{2}$ input. ACS Sustain Chem Eng 7:1933-1943

Wada H, Mizusawa N (2009) The role of phosphatidylglycerol in photosynthesis. In: Wada H, Murata N (eds) Lipids in photosynthesis: essential and regulatory functions. Springer, Berlin, pp 243-263

White DA, Rooks PA, Kimmance S, Tait K, Jones M, Tarran GA, Cook C, Llewellyn CA (2019) Modulation of polar lipid profiles in Chlorella sp. in tesponse to nutrient limitation. Metabolites 9:39

White DA, Pagarette A, Rooks P, Ali ST (2012) The effect of sodium bicarbonate supplementation on growth and biochemical composition of marine microalgae cultures. J Appl Phycol 25:153-165
Wolf F, Nemethy E, Blanding J, Bassham J (1985) Biosynthesis of unusual acyclic isoprenoids in the alga Botryococcus braunii. Phytochemistry 24:733-737

Wykoff DD, Davies JP, Melis A, Grossman AR (1998) The regulation of photosynthetic electron transport during nutrient deprivation in Chlamydomonas reinhardtii. Plant Physiol 117:129-129

Yang D, Song D, Kind T, Ma Y, Hoefkens J, Fiehn O (2015) Lipidomic analysis of chlamydomonas reinhardtii under nitrogen and sulfur deprivation. PLoS ONE 10:e137948

Yeh KL, Chang JS, Chen WM (2010) Effect of light supply and carbon source on cell growth and cellular composition of a newly isolated microalga Chlorella vulgaris ESP-31. Eng Life Sci 10:201-208

Yoshimura T, Okada S, Honda M (2013) Culture of the hydrocarbon producing microalga Botryococcus braunii strain Showa: Optimal $\mathrm{CO}_{2}$, salinity, temperature, and irradiance conditions. Bioresour Technol 133:232-239

Zhao LS, Li K, Wang QM, Song XY, Su HN, Xie BB, Zhang XY, Huang F, Chen XL, Zhou BC, Zhang YZ (2017) Nitrogen Starvation impacts the photosynthetic performance of Porphyridium cruentum as revealed by chlorophyll $a$ fluorescence. Sci Rep $7: 8542$

Zhila NO, Kalacheva GS, Volova TG (2005) Effect of nitrogen limitation on the growth and lipid composition of the green alga Botryococcus braunii Kutz IPPAS H-252. Russ J Plant Physiol 52:311-319

Zhuang X, Chappell J (2015) Building terpene production platforms in yeast. Biotechnol Bioeng 112:1854-1864

Publisher's note Springer Nature remains neutral with regard to jurisdictional claims in published maps and institutional affiliations. 